TI 2014-040/V

Tinbergen Institute Discussion Paper

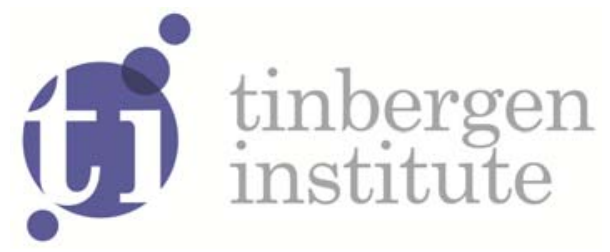

\title{
Insurance, Entrepreneurial Start-Up, and Performance
}

\author{
Mette Ejrnæs' \\ Stefan Hochguerte/2
}

1 University of Copenhagen, Denmark;

2 Faculty of Economics and Business Administration, VU University Amsterdam, and Tinbergen Institute, the Netherlands. 
Tinbergen Institute is the graduate school and research institute in economics of Erasmus University Rotterdam, the University of Amsterdam and VU University Amsterdam.

More TI discussion papers can be downloaded at http://www.tinbergen.nl

Tinbergen Institute has two locations:

Tinbergen Institute Amsterdam

Gustav Mahlerplein 117

1082 MS Amsterdam

The Netherlands

Tel.: +31(0)205251600

Tinbergen Institute Rotterdam

Burg. Oudlaan 50

3062 PA Rotterdam

The Netherlands

Tel.: +31(0)10 4088900

Fax: $+31(0) 104089031$

Duisenberg school of finance is a collaboration of the Dutch financial sector and universities, with the ambition to support innovative research and offer top quality academic education in core areas of finance.

DSF research papers can be downloaded at: http://www.dsf.nl/

Duisenberg school of finance

Gustav Mahlerplein 117

1082 MS Amsterdam

The Netherlands

Tel.: +31(0)20 5258579 


\title{
Insurance, Entrepreneurial Start-Up, and Performance*
}

\author{
Mette Ejrnæs \\ University of Copenhagen \\ mette.ejrnesdecon. ku.dk \\ and \\ Stefan Hochguertel \\ VU University Amsterdam \\ Tinbergen Institute \\ s.hochguertelevu.nl
}

26 March 2014

\begin{abstract}
Availability of (partial) insurance mechanisms is arguably important for the decision of (riskaverse) workers to start up a risky entrepreneurial venture. Using administrative data from Denmark, where unemployment insurance (UI) is available to both wage earners and self-employed on a voluntary basis, we estimate the causal effect of UI cover on the self-employment choice of wage earners after instrumenting for the UI choice. The instruments we use are based on a series of policy variations that took place at three points in time during an observation period spanning three decades: only UI covered individuals could under certain conditions qualify for an early retirement (ER) program. Changes (reforms) in the eligibility conditions of the program that affected different age groups differentially at these three different points in time identify the UI choice process. Results show that the causal effect of insurance on the probability of starting up a venture is positive for would-be entrepreneurs, in contrast to correlations in the data or uninstrumented estimates. Using firm data, we also investigate how the newly insurance-induced entrepreneurs fare relative to their uninsured peers. Results suggest that they survive longer, but are not more likely to employ any workers or to make higher or lower profits.
\end{abstract}

Keywords: self-employment, insurance, entrepreneurs, unemployment, panel data, early retirement EconLit subject descriptors: C350, J260, J620, J650, L260

\footnotetext{
*Work on this paper started while Hochguertel enjoyed the hospitality of the Department of Economics at the University of Copenhagen during a sabbatical. We thank Rui Baptista, Eric Bartelsman, John Friedman, Hans Hvide, Martin Junge, Marike Knoef, conference participants at the International Conference on the Dynamics of Entrepreneurship (ZEW Mannheim), the Danish Econometric Society Meeting, the NBER Summer Institute, the Econometric Society European Meetings, the First European Workshop on Entrepreneurship Economics/8th Tinbergen Institute Conference, and the CAM Microeconometrics Workshop; as well as seminar audiences at Copenhagen Business School, KORA (Danish Institute for Local and Regional Government Research), Lund University, VU University Amsterdam (Economics lunch, and FEWEB-FaDo) for critical questions and suggestions. Partial funding through a Velux Visiting Professor Scholarship by the Villum Fondet is gratefully acknowledged. Both authors thank the Economic Policy Research Network Copenhagen for financial support, and the Centre of Applied Microeconometrics (CAM) at the University of Copenhagen for facilitating data access to data servers of Statistics Denmark. Bjørn Meyer provided excellent research assistance.
} 


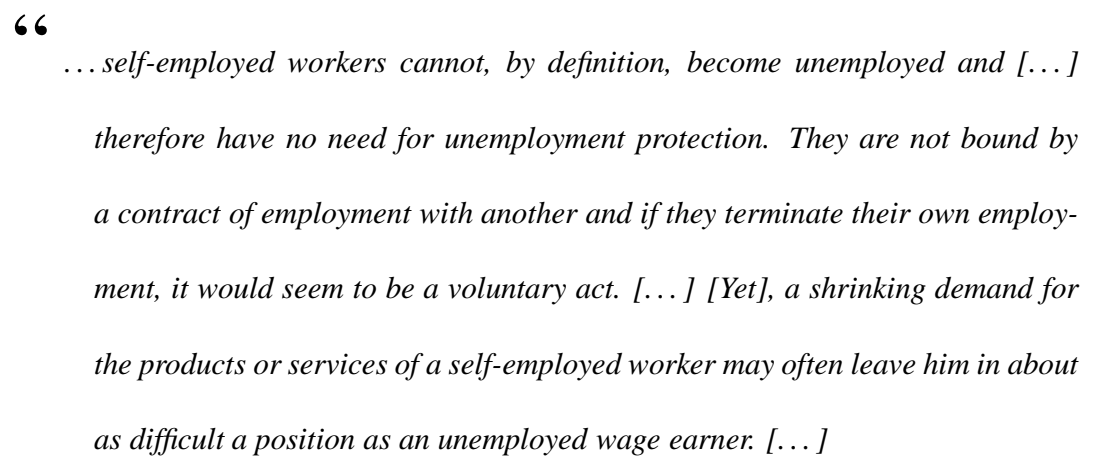

$\operatorname{ILO}(1955$, p. 50)

\section{Introduction}

\subsection{Insurance, Self-employed, and Entrepreneurs}

The possibility of failure is inherent in being an entrepreneur, and as the quote above suggests this may leave the unsuccessful business owner in a position as difficult as an unemployed wage earner. Such difficulties have been recognized by policy makers and providing the self-employed with better access to social insurance cover now ranks highly on the agenda (e.g., European Parliament (2014)).

Economic literature strongly suggests that insurance provision encourages risk taking, in particular that workers may be induced to start a business that they otherwise would refrain from. Combined with the perception that small firms are important drivers of technological progress and employment growth, bringing about innovation in technical processes and marketable products, policies that encourage entrepreneurial risk taking through enabling access to or inducing take-up of insurance, may hence be seen as instrumental for societal dynamics and creation of welfare. On the other hand, inducing individuals to engage in activities that are of questionable ex ante quality just because they can afford to do so, is socially inefficient.

We show in this paper that income insurance provision can indeed causally lead to higher startup rates, without having detrimental repercussions for the average quality of new firms. Our evidence is from Denmark, where unemployment insurance (UI) is both voluntary and available to both wageearners and self-employed. Anyone can decide whether or not to become member of a (often industry specific) UI fund (insurance association). This allows us to compare workers that are insured with those that are not before they may transition into self-employment. 
Denmark's institutional make-up is remarkably neutral to employment mode: the self-employed are subject to the same (or very comparable) access rules, premiums, and benefit eligibility criteria as wage employed individuals. This fact offers a unique opportunity to study the effect of potential UI protection, since the insurance mechanism per se is not targeting or in any specific way supporting the self-employed or those that want to become self-employed. The voluntary aspect of the arrangement also counters an important economic argument against social insurance: no-one is forced to pay membership dues, so the insurance scheme will not interfere to first order with liquidity needs of cash-strapped would-be entrepreneurs.

\subsection{Approach}

The question whether insurance is conducive to start-up is an important one to ask but not an easy one to answer. The main reason for the difficulty lies in the absence of formal insurance mechanisms and the lack of variation in the data. In Denmark, UI is formal insurance, that is, if the conditions for eligibility are fulfilled, benefits can be claimed. Since participation in the insurance scheme is voluntary, idiosyncratic variation in the data is observed in the Danish case.

The voluntary nature of UI implies, on the other hand, that there will be sorting effects within a heterogeneous population into insurance. These may create an endogeneity problem, in particular since tastes for insurance and entrepreneurship may be correlated. To instrument for the insurance choice, we exploit exogenous variation due to policy rules that induce insurance take-up.

Specifically, an early retirement (ER) program open only to members of UI funds provides the clue to our identification strategy. Program participants that wanted to keep the option of retiring early needed to enroll in the ER program (and thus insure themselves) far ahead of the ER period. For instance, in the period before the year 1992, 50 years was the latest enrollment age (or, threshold age) leading to ER benefit eligibility from age 60 on.

Figure 1 shows the UI fund enrollment rate for workers aged 47 in 1992. To become eligible for ER Fig. 1 when 60, a reform in 1992 demanded these people join the UI system immediately. The vertical jump illustrates the force of the UI enrollment incentive caused by the 1992 ER reform. Other cohorts faced different threshold ages, as we shall show.

Our data span the period from 1980 to 2009. In total, three reforms of the ER system were imple- 
mented (in 1992, 1999 and 2007/8), that reduced the ER eligibility age in three discrete steps from 50 to 32, with those cohorts that happened to be older than the reduced threshold age at the time of reform having to join UI funds immediately — and thus receiving unemployment insurance protection—in order to stay ER eligible.

Our study of the data suggests autonomous patterns in the age, time, or cohort dimensions that determine both UI enrollment and self-employment start-up. Therefore, using the changed ER incentives that affected different cohorts in different years differentially we retain a strong source of identification. We use the (series of reforms in the) ER eligbility rules as instruments for UI take-up in the first stage of an instrumental variables (IV) estimator that estimates the probability of transitioning from wageinto self-employment. We allow both insurance and self-employment entry choices to be affected by demographics, taste shifters, income and wealth. Importantly, we also allow for a very flexible way of incorporating age and period effects, and for individual fixed (FE) or random (RE) effects (in FE models, cohort effects are taken care of by the FE). Even though we identify a local average treatment effect (LATE), the estimate is obtained from very different strata of the population since our data covers a period of fully three decades, and several reforms were implemented over time priming different cohorts.

We condition the data on the population of prime aged Danish males outside agriculture, but impose no other constraints in terms of industry affiliation, occupation, firm characteristics or other observables. Raw data suggest an average year-on-year transition rate into self-employment of just under $1 \%$. Insured workers have a $0.8 \%$ probability, and uninsured workers a $1.5 \%$ probability to enter self-employment.

The negative association between insurance and start-up survives (if muted) in a simple, uninstrumented self-employment transition regression, taking into account observed and unobserved heterogeneity. Using the ER reforms as orthogonal shifters for UI inflow, however, we measure a very strong and positive causal effect of insurance on start-up of 1.2-1.8 percentage points.

Our central estimate suggests that important parts of the endogeneity bias are transmitted through time-varying unobservables (for example, individual-specific unemployment risk or health shocks) that are not accounted for by classically perceived as 'fixed' parameters such as risk aversion or entrepreneurial ability.

This paper does not evaluate the effect of start-up subsidies for the unemployed. Hence, we do not 
include in our analysis individuals that are initially unemployed. ${ }^{1}$ Our paper instead exploits the levelplaying field UI design for workers that may or may not choose to become self-employed as there are no occupation-specific incentives or disincentives to take up insurance; conversely, there are no (large) UI-specific aspects that favor or disfavor self-employment over wage employment. Among the many sensitivity checks that we perform, however, is an exclusion of workers from the sample that may have been threatened with layoff due to imminent firm closure. As we find no difference in causal effect estimates, we conclude that we find a genuine impact of insurance on workers that are free to choose their employment mode.

We then investigate in separate analyses the mid-term success of new entrepreneurs that were induced to take up insurance. The focus on performance is important when evaluating the success of policies that promote business creation. We consider a broad range of outcomes, from survival as selfemployed three and five years ahead, to future employment creation, profit generation as well as a range of other financial performance measures. Uninstrumented results show that insured entrepreneurs are more likely to survive as self-employed, but generate less profits compared to insured entrepreneurs. The important lesson that the data teaches us, however, is that there is no evidence that the causally insurance-induced entrepreneurs are any different (not better, and not worse) in terms of economic performance than others. We conclude that insurance 'opens the door' to entrepreneurship. Gauging the total effect of UI on start-up from a reduced form model we find a lower bound of nearly $5 \%$ over the entire 30 year observation period. The UI system may have additional effects lasting beyond the startup phase- the monotonicity in UI enrollment that is partly induced by the ER incentive keeps people insured and may keep people in self-employment for the rest of their working lives.

\subsection{Insurance Mechanisms in the Literature}

The evidence of an ex ante effect of insurance on start-up comes primarily from two insurance mechanisms studied with data from the United States: the possibility of a fresh start in bankruptcy legislation, and the removal of job-lock disincentives in health insurance. There is no direct empirical evidence, as far as we know, on the UI margin, since in most countries UI is either not available at all to the self-

\footnotetext{
${ }^{1}$ Denmark has, as other countries, specific start-up schemes for unemployed former workers. A French scheme is described and evaluated in Hombert et al. (2013). For Norway, Røed and Skogstrøm (2013) evaluate the effect of changing UI benefit duration on transitions out of unemployment to either employment or self-employment.
} 
employed, or it is available to all by way of compulsory insurance, not offering interesting variation for the population of potential start-ups. ${ }^{2}$

Bankruptcy protection becomes relevant when the bankruptcy code allows the proprietor of a failed firm to keep some assets after debt discharge. The law provides partial insurance by making possible a 'fresh start'. This is the case for Chapter-7 bankruptcy filings in the United States, and the variation in observational data comes about by asset exemption-levels being state-specific. Such variation has been exploited in empirical work (Fan and White, 2003). In addition, the 2005 reform of the US bankruptcy code changed a number of provisions at the federal level, making debt discharge more cumbersome, and leading to increased prevalence of firms with limited liability status (Paik, 2013). A number of recent studies such as Primo and Green (2011), Lee et al. (2011), or Jia (2011) looks at how cross-country or cross-state variation in bankruptcy laws affects the proportion of self-employed in the labor force. In summary, leniency begets entrepreneurship. Note, however, that higher exemption levels may be associated with higher default rates, driving up interest rates and thus hindering start-up investments, or resulting in lenders rationing the borrowers (Berkowitz and White, 2004; Meh and Terajima, 2008; Akyol and Athreya, 2011).

The other main insurance-related mechanism discussed in the literature concerns the cost of health insurance. Gruber and Poterba (1994) document substantial variation in health insurance coverage rates among the self-employed in the United States. They estimate a price effect from a tax-subsidy on health insurance demand using the 1986 Tax Reform Act (TRA86) variation. Following Madrian (1994), a number of papers investigates the idea that losing access to employer-sponsored health insurance keeps people from moving from wage to self-employment (job lock). Velamuri (2012) uses the introduction of the TRA86 fiscal deductibility of private health insurance premiums to study the impact on the fraction of self-employed women with data from the US Current Population Survey (CPS). She finds that single women and married women who are not covered by their spouses' insurance are more likely to be selfemployed after the tax subsidy was introduced compared to married women covered by their partner. Gumus and Regan (2009) study the effect of a series of changes in the TRA86 tax subsidy on healthinsurance take-up and self-employment entry (and exit). They find a small significant effect on entry

\footnotetext{
${ }^{2}$ Giannetti and Joensen (2013), using similar data to ours, look at the intensive margin of varying the UI benefit level on start-up. Their focus is on the intention-to-treat effect that abstracts from modeling the insurance choice.
} 
with CPS data. Heim and Lurie (2010) likewise study the effect of the increase in deductibility, but use US tax return data, finding significant effects on both entry and exit. Heim and Lurie (2013) use the same data and extend the analysis to take into account between-state variation with respect to health insurance regulation. Lightly-regulated states show highest responses. Fairlie et al. (2011) instead use a regression-discontinuity approach that distinguishes between those entering self-employment before and after the critical age of 65 , from which on universal Medicare coverage leads to within-sample variation in insurance status. The authors find a significant treatment effect. DeCicca (2010) uses a reform of health insurance in New Jersey in 1993 that made it easier for self-employed to be covered by health insurance. He finds an increasing fraction of self-employed in New Jersey relative to other states. Health insurance cost thus determine occupational choice, although the insurance effect is indirect as health insurance does not insure entrepreneurial risk, but at most a correlated background risk.

\subsection{Contribution}

Our paper contributes to the literature in various important ways. First, we consider a formal (partial) insurance mechanism that is of first-order importance to the income generation process of small business owners. There are not many such programs available that one can think of. We suspect that risk averse would-be entrepreneurs will, in the absence of such formal mechanisms, resort to informal ways to selfinsure, and surmise that those effects will be harder to identify empirically. ${ }^{3}$ Second, we use micro panel data that cover the entire population of a country and are thus able to precisely measure effects on small transition probabilities that are associated with overwhelming heterogeneity. Third, we have a large array of variables at our disposal that we are able to use as controls, among which measures of wealth, industry, labor market history, and health (sickness benefit receipts), all of which belong to the set of time-varying factors that determine choices. Fourth, and most importantly, we can determine the causal effect of insurance on start-up using idiosyncratic variation in insurance status, and hence control the insurance choice. Many papers in the literature analyze self-employment rates or self-employment entry in reduced-form settings that cannot distinguish directly between the insured and the uninsured, or that treat insurance status as exogenous (such as with exogenous location choice when studying the between-

\footnotetext{
${ }^{3}$ This is in fact what we find. In our specifications, we allow for competing informal sources of self-insurance through prior accumulated wealth and through spouse's unused earnings potential. Neither channel is very strong.
} 
state variation in bankruptcy protection). Using the policy variations induced by three major reforms we are able to construct six exogenous instruments that shift insurance without having first-order effects on the entrepeneurial start-up decision. Fifth, our paper is one of the first to look at post-transition outcomes. While the bankruptcy and health insurance literatures identify an insurance mechanism, they are largely silent on characterizing the performance of the treatment group. ${ }^{4}$

The rest of the paper is organized as follows: Section 2 sketches relevant institutional settings that are important for an understanding of the generation of the data and our empirical identification strategy. Section 3 introduces a simple model of occupational and insurance choice. Section 4 sketches details of our empirical approach. Section 5 presents the data we use along with descriptives illuminating salient patterns and trends. Section 6 presents empirical estimation results. Section 7 provides brief conclusions.

\section{Institutions}

In this section we provide a short description of the legal and institutional setting for Danish entrepreneurs. We cover the period 1980-2009 and focus in particular on the income insurance aspects for entrepreneurs. We shall also explain in some detail the early retirement (ER) system, which is integrated into the unemployment insurance (UI) system. There were important reforms in ER eligibility rules-we exploit these in our empirical approach. ${ }^{5}$

\footnotetext{
${ }^{4}$ There are related papers that look at post-reform outcomes or outcomes in relation to institutional variation in slightly different contexts. Hombert et al. (2013) study the case where unemployed former workers would retain their entitlements to UI benefits if their start-up venture failed. They compare industry groups according to pre-reform prevalence of soleproprietorship. They then compare outcome measures post-reform and post start-up. Røed and Skogstrøm (2013) study transitions from unemployment to self-employment and compare incomes after one year. Cerqueiro and Penas (2011) study the effect of across-state variation in bankruptcy protection (i.e., the intensive margin of insurance) on the financing structure of firms (own capital $\mathrm{v}$ bank credit), firm growth rate (employees and revenues) and on exits. Other types of government intervention conducive or detrimental to start-up have been investigated and identified as causal mechanism for business creation and performance. Among those feature zoning laws (Bertrand and Kramarz, 2002), banking regulations (Kerr and Nanda, 2009), or administrative procedures (Branstetter et al., 2013), and their implications for employment outcomes have been investigated.

${ }^{5}$ This section draws on Ejrnæs and Hochguertel (2013), Economic Council (2011, p. 176-177, Box II) and Pedersen and Huulgaard (2007) .
} 


\subsection{Insurance Mechanisms}

Starting up involves substantial risks borne by the individual entrepreneur. In Denmark, most of the self-employed run small unincorporated firms in sole proprietorship and $90 \%$ of all firms have less than 10 employees (in 1999). Among newly started firms about half survive the first three years and more than half of those who go bankrupt do not have any employees (see Statistics Denmark, 2009, 2010).

Self-employed entrepreneurs are protected by two main institutional income insurance mechanisms: bankruptcy proceedings and unemployment insurance. There are two types of proceedings in which the bankruptcy law foresees: those extending to corporate liabilities, and those intended for personal liabilities including debt of unincorporated businesses. The latter protection was included in the Bankruptcy Reform Act of 1984, making discharge of some part of debt possible for small firms, but typically involving a repayment plan out of income for the remainder of non-discharged debt. We argue, however, that bankruptcy proceedings are not of first-order importance for the majority of self-employed entrepreneurs in Denmark, unlike in the United States. Armour and Cumming (2008) list the various provisions of a number of bankruptcy acts in international comparison and show that the Danish legislation is substantially less forgiving than the US bankruptcy act. Unlike in the United States where insolvency is not a necessary condition for bankruptcy and debt discharge, filing for bankruptcy in Denmark is tied to being "hopelessly indebted and [. . . ] the proceedings [being] warranted by the circumstances of the debtor" (Alexopoulos and Domowitz, 1998). Out-of-court settlements are subject to rules and discretionary negotiation outcomes. Typically, taking this route is associated with considerable delays. Thus, bankruptcy, insolvency, and debt restructuring will apply only in the minority of cases where a self-employed person terminates his business. In many cases, decreasing or non-positive profits will be reason enough to close shop, without being insolvent.

The main income insurance provided in Denmark is the unemployment insurance system. Denmark is one of the very few countries where unemployment insurance is voluntary and where, quite uniquely, also the self-employed can insure themselves along with wage employed workers (Schoukens, 2000). ${ }^{6}$ Comparing the number of registered firm bankruptcies (including the corporate ones) with the number of self-employed that subsequently register as unemployed, shows that the latter figure exceeds the former

\footnotetext{
${ }^{6}$ Sweden and Finland are the other examples mentioned in Parsons et al. (2003).
} 
by $50 \%$ on average. ${ }^{7}$

The insurance system is organized around about 35 private, industry/occupation-specific UI funds. ${ }^{8}$ A typical UI fund is a not-for-profit organization without selection restrictions for applicant members. UI funds finance UI benefits through membership fees, payroll taxes and government subsidies. ${ }^{9}$ There are mainly two funds that focus on the self-employed, DANA and ASE. The funds are free (within legal limits) to determine regulation of benefit entitlements, although there tends to be close alignment between funds. The eligibility rules as well as level and potential duration of benefits are in general the same for wage earners and self-employed, although there are small differences. Wage earners are allowed to insure themselves either as full-time workers or part time workers, whereas self-employeds' insurance status is restricted to always being full-time. To illustrate, according to ASE regulations, the self-employed entrepreneurs can file for UI benefits in cases where all of the following conditions apply: ${ }^{10}$

- the UI fund membership has lasted for at least 12 months

- the applicant has worked at least 52 weeks full-time during the past 3 years; both work as a wage earner or work as a self-employed can be counted in for the 52 weeks ${ }^{11}$

- the applicant enrolls with the public job center from the first day of unemployment

- the applicant is willing to take on any job as a wage employee; the benefit recipient must perform active job search while receiving compensation

- the business is sold, liquidated, or leased (mutually irrevocably for a period of at least five years).

The self-employed may also temporarily suspend their business and register as unemployed upon experiencing an extraordinary event, such as fire. In such cases, the event must be beyond control of the self-employed and excludes ordinary industry risk. The idea is to insure idiosyncratic exogenous shocks. Incomes must have been critically exhausted.

\footnotetext{
${ }^{7}$ See Ejrnæs and Hochguertel (2013). Numbers exclude the agricultural sector.

${ }^{8}$ The number of UI funds that we count in our data varied over the period from 58 in 1980 to 30 in 2006. In what follows, we shall interchangeably speak of UI fund membership and being insured.

${ }^{9}$ Lentz (2009) reports that the average worker pays about $1 / 3$ of the actual premium, the rest being subsidies.

${ }^{10}$ The rules applied until 2009 and may have changed since.

${ }^{11}$ This rule has changed during our sampling period. The period used to be 6 months within the last 3 years.
} 
Benefit duration can be characterized as generous in international comparison: This used to be 84 months until 1996, when it was reduced to 60 months; during the 1990s there have been changes also to include activation programs with mandatory participation that starts within 12 months of first registration. In 1998 the duration was further reduced from 60 months to 48 months.

Parsons et al. (2003) report for the year 1995 that the contribution paid by an individual amounted to about 3,600 DKK for a wage employed worker and to about 4,000 DKK for a self-employed person. These figures exclude administration costs, which can vary substantially across UI funds. The contribution is independent of earnings. For one of the large UI funds for self-employed (ASE) the contribution amounts to about 2.5 percent of the benefit.

For workers the benefit level is $90 \%$ of previous earnings subject to a floor and a ceiling. For selfemployed the amount of the UI benefit is a function of an average of profits of the two best performing annual financial reports within the last five financial years during which the applicant was UI fund member. ${ }^{12}$ The parameters of that function are set centrally and are not at the discretion of the individual fund: the benefit rate equals $90 \%$ of the average profit (excluding interests, including depreciations and labor market contribution), bracketed by a ceiling and a floor. The ceiling/floor correspond to that for workers. ${ }^{13}$ In the data, the majority (about three in five) of self-employed would face potential benefits corresponding to the ceiling, and much of the rest (about one in three) would see potential benefits corresponding to the floor.

Jobless persons not covered by UI fund benefits, including those who have exhausted the maximum benefit period, can receive social assistance. The social assistance depends on spousal income and individual circumstances, but is for the vast majority considerably lower than the UI benefit. To receive social assistance the requirements are that the person is registered as unemployed and is actively searching for a job. Municipalities can, however, coerce recipients to work in public sector jobs.

The voluntary nature of the UI insurance leads people to enroll when they expect to need protection most. That is, there will be strong time patterns over the business cycle, but also patterns for certain age groups or cohort members. Such patterns are not always very discernible in two-dimensional pictures,

\footnotetext{
${ }^{12}$ For those who have been self-employed less than three years the benefit is calculated on the basis of the last earnings as wage earner.

${ }^{13}$ The ceiling amounted to a gross income of about 135,000 DKK p.a. in 1996, 173,000 DKK p.a. in 2006.1000 DKK $\approx$ 134 Euro. The floor amounts to $82 \%$ of the ceiling, and is essentially due to minimum wage regulation that applies for wage employed (thus, about 142.000 DKK p.a. in 2006). For temporary suspensions, the benefit rate equals $80 \%$ of the ceiling.
} 
but Figure 2 provides what we might call a heat map of UI entry. The column space is made up of the Fig. 2 years in our sample (from 1981, since we measure new UI fund members in year $t$ compared to $t-1$ ). The row space is made up of year-of-birth cohorts, and cells thus allow to define ages. Age changes from the south-west (low) to the north-east (high). The map thus contains empirical entry probabilities into UI.

Different levels of empirical entry rates as observed in the data are colored from green (low) to red (high). It is clear that older people are less likely to enroll (many of them are enrolled already), one may detect time patterns and possibly regularities for particular cohorts. There are, however, strong patterns ranging across the picture that are not explained by either age, cohort, or year effects alone. The most salient of those have to do with incentives emanating from the Early Retirement System, as we shall explain next.

\subsection{The Early Retirement System and Its Reforms}

The Danish ER system has been through three major reforms during our study period: in 1992, 1999 and 2007/8. We start by describing the system from 1980 to 1992 and then describe the three reforms in detail. The ER system, allowing retirement at reduced pension benefits from age 60, is separately organized from the old-age retirement pension system, which is compulsory and foresees in retirement from age 67 onward. Rather, ER is integrated in the UI fund system and the ER option is open exclusively to UI fund members. The ER scheme was introduced in 1979, with an eye toward general labor market conditions at the time, and politically supported with the argument that it would bring relief to "wornout' blue-collar workers. However, access to the ER system is possible for both blue- and white-collar workers, and for both wage earners and self-employed. The latter have to sell their business before they can claim benefits. ER provides insurance through the possibility of retiring from labor market activity at older ages. This may be relevant from the perspective of a young self-employed person who, when old might find it difficult to find a paid job in the event of his firm failing. Until 1992 UI fund members aged 60 and older used to qualify if they had been enrolled in the UI system for the last 10 years, typically leading to a spike in the enrollment hazard at threshold age 50 .

In the period before 1999, there is no additional premium associated with benefiting from the ER plan. In other words, ER could be had at zero marginal cost for the interested participant. ER benefits 
correspond to the UI benefits, as discussed earlier. The early retirement benefit is in general higher than the (flat-rate) old-age pension and is not means-tested. However, once an individual has commenced drawing ER benefits, other significant labor market activities are precluded. ${ }^{14}$

The first major reform of the early retirement system took place in 1992. This reform concerned a policy shift that required continued membership of at least 20 (instead of 10) years before retirement, implying the latest age for joining a UI fund decreased from 50 to 40. Individuals aged between 40 and 50 in 1992 were required to join the UI fund in 1992 and stay members until 60 if they were to collect ER benefits.

Figure 3 illustrates in a schematic overview how different cohorts are affected differently by this and Fig. 3 subsequent reforms. The head column contains year of birth covering the relevant range in our data, the head row contains years in our data, entries are resulting ages. Gray areas are ages excluded from the data, the white and colored regions are included. The various colored areas indicate various regimes that applied for various cohorts or age groups at different points in time. The Table thus tries to make transparent that the ER policy reforms affected different age groups differentially in different years. The relation with the heat map of empirical entry rates (Figure 2) is immediately obvious. This comparison provides prima facie evidence that the ER incentive shifts UI coverage rates. We shall get back to this below in Section 4.

The next reform took place in 1999. It instituted five major changes: the maximum length of the ER period changed, ER-eligibility rules changed, an independent ER contribution was introduced, new rules of how to calculate retirement benefits were implemented, and a bonus for not using the retirement option was introduced. In correspondence to lowering the old-age pensionable age from 67 to 65 in 1999, ER benefits could be drawn during ages 60 to 64 . The second element of the reform was to increase the required number of membership years in a UI fund from 20 to 25 years. Similar to the 1992 reform, transitional rules applied to the cohorts between 35 and 39 years of age in 1999. The third element of the reform was the introduction of a separate ER contribution. The contribution should be paid for at least 25 years with those older than 35 years paying the contribution from 1999 until the age of 60. This contribution amounted to 5,520 DKK in 2012. ${ }^{15}$ The fourth element of the reform

\footnotetext{
${ }^{14}$ Small-scale activities, amounting to not more than 200 hours worked per year, were admissible.

${ }^{15}$ This contribution is additional to the fee for the UI fund. The latter amounted to about 4,000 DKK in 2012 (depending on UI fund). Note that with the introduction of the ER contribution in the 1999 reform the fee for UI was actually lowered, and
} 
was a change in the benefit level formula, regarding taking into account the level of private pensions available to the individual. Benefits were reduced depending on the size of such alternative pension claims. Furthermore, the ER benefit recipients' cap on admissible hours worked (200 per year, see note 14) was removed. The last reform element was a bonus given to those who were eligible for ER but decided to postpone ER beyond the age of 62. The size of the bonus increased for each quarter of postponement until reaching the age of 65 .

OECD (2006) illustrates the incentive effects of the ER system for the sub-periods 1992-1998 and 1999-2006 by showing that the 'implicit tax on continued work' from age 60 onward exceeded 50\% in the early period. Due to these incentives and because of its generosity, ER became a very popular exit route from the labor force, eventually causing financial strain to the system and hampering productivity growth. In the second period after the 1999 reform, the implicit tax estimate decreased to about 30\%.

The 2007/8 reform increased the required number of UI fund membership years to 30 for ER eligibility purposes. The ER entry age was in addition gradually increased to 62 for cohorts born in 1963 or later. This implied that individuals desiring to benefit from the ER system needed to be UI members from the age of $32 .{ }^{16}$ The empirically relevant variable for enrollment is the implied age threshold and not membership duration per se. ${ }^{17,18}$ But the 2007/8 reform also introduced an additional option to join for individuals that were older than their threshold age, but that were at least 15 years removed from ER entry ages. We call such individuals 'latecomers'. They would face reduced future ER benefits, however.

\footnotetext{
only grew very slowly since.

${ }^{16}$ Furthermore, it was announced that by 2019 the ER entry age would be 62 for all cohorts. A dependence of ER (and old-age pension) entry ages on the development of life expectancy was also introduced. Such changes are not subject of the present analysis.

${ }^{17}$ To be precise, the rules are framed in terms of minimum numbers of contribution years. When we speak of minimum required enrollment periods of $10(20,25,30)$ years, the actual rules allow for some additional slack by specifying that the individual needs to have paid contribution at least during $10(20,25,30)$ out of the last $20(25,30,35)$ years. For the purposes of constructing our instrument in our empirical work we rely on the implied minimum enrollment period of $10(20,25,30)$ years, since this is not subject to choice.

${ }^{18}$ The implementation of the 2007/8 reform allowed a number of practical exceptions, leading to changes becoming relevant for many individuals only as of January 2008. In our empirical analysis we have considered the 2007/8 reform to alternatively come into effect in 2007 or 2008, without, however, finding our main conclusions to be affected.
} 


\section{A Simple Model of Occupational and Insurance Choice}

\subsection{The Environment}

We set up a simple static model illustrating the main mechanisms through which insurance affects the entrepreneurial start-up decision. The model is inspired by the occupational choice model of Evans and Jovanovich (1989) but extended with the risk of business failure. We capture this event by allowing entrepreneurs to become unemployed. Wage-earners can become unemployed as well. Agents can insure themselves against unemployment by taking out insurance. ${ }^{19}$ There is no labor supply (hours) choice, and we ignore a non-monetary utility of being an entrepreneur.

Individuals have recourse to an exogenous, initial wealth level $A$, and to income $Y_{\omega}^{d s}$. Income depends on three magnitudes: a binary state of the world $\omega \in\{0,1\}$ (unemployed or working), a binary insurance indicator $s \in\{0,1\}$ (not insured or insured), and a binary occupation indicator $d \in\{0,1\}$ (wage earner or entrepreneur). Agents can choose $s$ and $d$. As entrepreneur $(d=1)$, the agent also needs to choose a level of investment (to be specified below). Decisions need to be made before the state of the world $\omega$ is revealed.

Agents maximize expected utility of income. We assume a standard concave utility function $u$, where $u^{\prime}>0$ and $u^{\prime \prime}<0 .{ }^{20}$ The state of unemployment $(\omega=0)$ occurs with an occupation-specific probability $\pi^{d}$. If $0.5>\pi^{1}>\pi^{0}$, entrepreneurship is inherently riskier than wage employment. The agent's problem is then

$$
\max _{d, s} \quad E U^{d s}=\pi^{d} \cdot u\left(A+Y_{0}^{d s}\right)+\left(1-\pi^{d}\right) \cdot u\left(A+Y_{1}^{d s}\right)
$$

where $E U^{d s}$ denotes expected utility, indexed on employment mode $d$ and insurance status $s$. Since both $s$ and $d$ are binary indicators, optimal choices can be determined by comparing expected utilities.

\footnotetext{
${ }^{19}$ We thus capture salient aspects of the institutional environment in Denmark. Standard approaches such as Kanbur (1979), Kihlstrom and Laffont (1979) and Vereshchagina and Hopenhayn (2009) have uncertainty in profits or project returns that entrepreneurs can generate.

${ }^{20}$ Low risk aversion or high risk tolerance is sometimes offered to explain why people choose entrepreneurship despite low average returns (e.g. Ekelund et al., 2005; Caliendo et al., 2009; Dohmen et al., 2011). This is in line with traditional occupational choice models (Kanbur, 1979; Kihlstrom and Laffont, 1979) that rely on preference heterogeneity to show that only the risk-neutral or least risk-averse select into entrepreneurship. Vereshchagina and Hopenhayn (2009), instead, describe a sorting mechanism induced by wealth or borrowing constraints and do not rely on preference heterogeneity. There is little supporting evidence, however, to suggest that small-scale entrepreneurs are risk-neutral or risk-seeking and have no demand for insurance.
} 
If the agent becomes unemployed $(\omega=0)$, he will receive

$$
Y_{0}^{d s}=s(B-P)+(1-s) H-d \cdot k
$$

Here, $B$ is the benefit level if insured, $B>0$, and $H$ is income if not insured. $H$ can be social assistance or subordinate informal insurance provided by spouse or family, $H \geq 0$. Taking out insurance involves having to pay a premium $P$, irrespective of $\omega$. Neither UI parameters nor income when uninsured depend on occupation. The entrepreneur-agent decides on the level $k$ of investment capital to pledge. We shall assume that he can convert his wealth $A$ dollar-for-dollar into business assets $k$.

If the agent does not become unemployed $(\omega=1)$, he receives

$$
Y_{1}^{d s}=(1-d) Y^{W}+d \cdot\left(\gamma k^{\alpha}-k\right)-s \cdot P .
$$

As employed wage earner, he receives fixed earnings $Y^{W}$, and as successful entrepreneur he produces income with a given technology, $\gamma k^{\alpha} \cdot \gamma$ captures entrepreneurial ability. We assume $\gamma>0$ and decreasing returns to the investment, $\alpha \in(0 ; 1)$.

Combining, the agent's problem is fully specified by

$$
\begin{array}{cc}
\max _{d, s} & d \cdot \max _{k}\left[\pi^{1} \cdot u(A+s(B-P)+(1-s) H-k)+\left(1-\pi^{1}\right) \cdot u\left(A-k+\gamma k^{\alpha}-s \cdot P\right)\right]+ \\
& (1-d) \cdot\left[\pi^{0} \cdot u(A+s(B-P)+(1-s) H)+\left(1-\pi^{0}\right) \cdot u\left(A+Y^{W}-s \cdot P\right)\right] .
\end{array}
$$

We sketch the solution stepwise by first examining an entrepreneur's investment choice $k^{s *}$ (indexed on insurance status $s$ ) and optimal insurance choice $s^{1 *}$ (Section 3.2). Subsequently we determine the optimal insurance choice $s^{0 *}$ of a wage earner (Section 3.3). Conditional on the obtained values we determine $d^{*}$ (Section 3.4). 


\subsection{The Entrepreneur}

\subsubsection{The Optimal Investment}

We can show (see Appendix B) that an entrepreneur's optimal investment $k^{s *}$ is in the interval $[0, \bar{k}]$ where $\bar{k}=(\alpha \gamma)^{1 /(1-\alpha)}$ maximizes the firm's profits. It depends on parameters as follows:

$$
\begin{aligned}
& k^{0 *}=k\left(\pi_{-}^{1}, H, A, \gamma, \alpha\right) \\
& k^{1 *}=k\left(\pi^{1}, B, P, A, \gamma, \alpha\right) \\
&-++? ?
\end{aligned}
$$

Subscripts below the symbols indicate the sign of the partial derivative of the function with respect to the argument in question. A question mark signifies that derivatives are impossible to sign without further assumptions. We shall use this notation also in what follows.

Given $\pi^{1}, A, \gamma$ and $\alpha$, the investment of an insured entrepreneur is always higher than or equal to that of an uninsured entrepreneur, $k^{1 *} \geq k^{0 *}$. The intuition behind this result is that an uninsured entrepreneur has to keep a larger fraction of his wealth as buffer in case of unemployment. The investment is equal if the probability of unemployment $\pi^{1}$ is either zero or one. The difference in the investment between the insured and uninsured $\left(k^{1 *}-k^{0 *}\right)$ depends on the value of the UI benefit $B$ and the UI premium $P$. If $B(P)$ is large (small) the difference in investment will be large. If $A$ tends to infinity, the difference between an insured agent and an uninsured agent diminishes.

Income $Y_{\omega}^{1 s}$ increases in $k$ for $k \in[0, \bar{k}]$. It follows that income (profit) of an insured entrepreneur is higher than that of an uninsured entrepreneur, $Y_{1}^{11} \geq Y_{1}^{10}$. This suggests that the causal effect of insurance on income (profits) as an entrepreneur is positive.

\subsubsection{The Insurance Choice}

Appendix B derives the insurance choice from comparing expected utilities with and without insurance at optimal values of $k$. In summary,

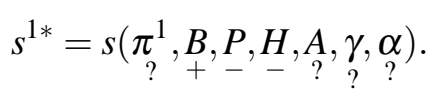

To develop some intuition for the effects of $\pi^{1}, A$, and $\gamma$, we provide a set of illustrative figures 
generated under some parameterization of our model.

The impact of wealth on insurance is ambiguous. For some values of $\pi^{1}, B, P, \gamma$ and $\alpha$ it will be the wealthy agents who will benefit most from an insurance. For other values it will be the least wealthy who benefit most. In Figure 4 we show an example where the least wealthy will choose an insurance Fig.4 while the wealthier individuals will not.

Interestingly, we can show that if the premium is sufficiently high then high-ability entrepreneurs have a larger demand for insurance than low-ability entrepreneurs. The reason is that the return to the investment is much larger for high-ability entrepreneurs. Therefore, the high-ability entrepreneurs will prefer to invest more and this will lead to a large income difference between the states of employment and unemployment. Insurance will decrease this gap and allow for higher investment (see Figure 5). Fig. 5 This suggests that offering insurance for entrepreneurs will not necessarily attract the agents with lowest abilities.

\subsection{The Wage Earner}

Wage earners only have an insurance choice. Similar reasoning (again, see Appendix B) shows that their insurance decision is determined as follows

$$
s^{0 *}=s\left(\underset{+}{\pi_{+}^{0}, B, P,{ }_{-}^{H}, \underset{?}{A}, Y_{+}^{W}}\right) .
$$

\subsection{The Occupational Choice}

We can determine the occupational choice conditional on insurance status from comparing expected utilities. Consider the decision of an uninsured agent. The choice depends on parameters as follows

$$
d^{0 *}=d\left(\pi_{-}^{1}, \pi_{+}^{0}, \underset{?}{H}, \underset{+}{A}, Y_{-}^{W}, \underset{+}{\gamma}, \underset{ \pm}{\alpha}\right)
$$

The wealth effect is in general ambiguous; while difficult to characterize in general, examples can be found of a positive wealth gradient in the entry to self-employment even in the absence of borrowing constraints. 
For insured agents we can similarly show that

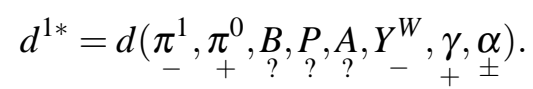

The same considerations about the wealth effect apply. Furthermore, if $\pi^{1} \geq \pi^{0}$ the benefit level $B$ will increase the likelihood of choosing to be an entrepreneur.

Now we compare the region in which an insured and an uninsured agent will choose to be an entrepreneur. In Figure 6 we show the contours of the difference in expected utility. In this particular Fig. 6 example, we see that there are more individuals who will choose to be an entrepreneur if they are insured, especially among the high-ability and low-wealth types. Furthermore, we see that the wealth gradient is much larger for uninsured compared to insured. This suggests that in this example insurance weakens the dependence on wealth.

It might also be interesting to compare the average income as entrepreneur for those who are insured with those who are uninsured. To do so we need to take account of two facts. On the one hand the insured will have a lower level of entrepreneurial ability than the uninsured, on average. On the other hand, the insured with the same level of ability will have higher income as an entrepreneur. Therefore it is not possible to sign the difference in average income between insured and uninsured entrepreneurs.

We end this section by summing up the main predictions of the model which we will take to the data. In the model we show that while keeping fixed the level of ability, wealth and perceived probability of unemployment, insurance will have a positive effect on the likelihood of start-up. We interpret this as a positive causal impact of insurance on the start-up probability. We also show that the correlation between insurance and start-up can be either positive or negative due to the endogeneity of the insurance status. Furthermore, we show that conditional on ability, wealth and the perceived unemployment probability, insured entrepreneurs will invest more than uninsured entrepreneurs, which again will lead to higher income for insured entrepreneurs compared to uninsured entrepreneurs. The prediction of the model is a positive causal effect of insurance on the investments and on earnings. The model also predicts that the correlation between investment and insurance can be either positive or negative. 


\subsection{Identification and Implications for Empirical Work}

We shall in this paper focus on presenting estimates based on empirical data, and have our specification guided (in a looser sense) by some of the predictions of our theoretical model. The main aspect is to uncover the effect of insurance status on the self-employment decision.

As we have shown in the previous subsections, having an unemployment insurance can affect the choice of occupation. However, it is also clear from the model above that the choice of insurance may be endogenous. From equations (2) and (3) it is clear that the choice depends on the (perceived) probability of becoming unemployed. The choice of occupation also depends on the unemployment probabilities. This simple fact could induce a correlation between insurance choice and occupation choice without being a causal relation.

However, unless we are able to fully control in our empirical work for (perceived) unemployment risk, the correlation between occupation and insurance cannot be interpreted as the causal relation that we are interested in. Other confounders such as ability as an entrepreneur, degree of risk aversion and access to informal insurance may lead to insurance status being endogenous to the occupational choice. In the results Section 6 we discuss the potential correlation between insurance and entry to entrepreneurship in more detail.

To identify the causal effect of insurance on the choice of occupation, we exploit the ER feature of the Danish UI system: for some agents (at some ages) additional benefits associated with the insurance are available, see Section $2 .^{21}$ The benefit $R$ is the option to retire early, which-depending on the time period - can be used at least $10(20,25,30)$ years after the insurance choice has been made. By assuming time-separability between today where the insurance choice is made and the future where the retirement option can be exercised, we can model the retirement option as an additive term enhancing utility, where $\beta$ is a discount factor. The problem of the agent is then

$$
\begin{array}{cc}
\max _{d, s} & d \cdot \max _{k}\left[\pi^{1} \cdot u(A+s(B-P)+(1-s) H-k)+\left(1-\pi^{1}\right) \cdot u\left(A-k+\gamma k^{\alpha}-s \cdot P\right)\right]+ \\
& (1-d) \cdot\left[\pi^{0} \cdot u(A+s(B-P)+(1-s) H)+\left(1-\pi^{0}\right) \cdot u\left(A+Y^{W}-s \cdot P\right)\right]+s \beta R .
\end{array}
$$

\footnotetext{
${ }^{21}$ This idea is also used in Ejrnæs and Hochguertel (2013), albeit with reliance on the 1992 reform only and studying somewhat different issues.
} 
Due to additivity, optimal investment and choice of occupation conditional on insurance status are unaffected by the additional benefit. Optimal insurance status will, however, be affected positively. This implies that the problem is

$$
\begin{aligned}
& s^{0 *}=s\left(\pi_{+}^{0}, \underset{+}{B}, \underset{-}{P}, \underline{H}_{-}^{H}, \underset{?}{A}, Y_{+}^{W},{ }_{+}^{R}\right) \\
& s^{1 *}=s\left(\pi_{?}^{1}, B, P,{ }_{+}^{H}, \underset{?}{A, \gamma}, \underset{?}{\alpha, R}+\underset{+}{\alpha} .\right.
\end{aligned}
$$

By using the variation in insurance status caused by the additional benefit we can identify the effect of insurance status on occupation. The identifying assumption is that the discounted value of the retirement option is uncorrelated with the unobserved individual effects such as unemployment risk, $\pi^{1}$ and $\pi^{0}$.

\section{Empirical Modeling and Implementation}

We rely on estimates from linear probability models where we allow for fixed or random individual effects and endogenous regressors that we instrument.

We can interpret the set-up as a two-equation system. The first equation (first stage) refers to the probability of becoming insured conditional on the instrument (lagged ER eligibility), and the second equation (second stage) refers to the probability of becoming self-employed conditional on lagged insurance choice. We lag the insurance choice once since the variable measures insurance status at a point late in the year (week 48, see page 24).

Introducing notation for the econometric model, let $y_{j i t}$ denote choice variable $j$ (say, the demand for insurance or the propensity to start up) for individual $i$ at time $t$. We model this as a function of a vector of observables $x_{i t}$, as well as unobservables, $\eta_{j i}$ and $\varepsilon_{j i t}$,

$$
\begin{aligned}
& \text { (insurance) } \quad y_{1 i t}=\quad \gamma z_{i t-1}+\beta_{1} x_{i t}+\eta_{1 i}+\varepsilon_{1 i t} \\
& \text { (start-up) } \quad y_{2 i t}=\alpha y_{1 i t-1}+\quad \beta_{2} x_{i t}+\eta_{2 i}+\varepsilon_{2 i t}
\end{aligned}
$$

In terms of our model sketched out in Section 3, these equations combine the self-employment decision conditional on insurance status (4) and (5) with the insurance choice (6) and (7).

In our baseline estimation, both equations allow for individual fixed $\eta_{j i}$ effects that can be arbitrarily 
correlated. Likewise, the idiosyncratic errors $\varepsilon_{j i t}$ between both equations are allowed to be correlated. We need to make the usual orthogonality assumption between the remaining, time-varying error in the instrumenting equation and the regressors and instruments used, and between the error in the instrumented equation and the instrument set conditional on regressors.

The individual fixed effects capture factors that are relevant for the two decisions of the agent that we model, but are unobserved by the econometrician. Those might include technology parameters such as entrepreneurial ability, or preference parameters such as risk aversion, but they might also proxy for access to external finance. These examples suggest that allowing for correlation among the unobservables is potentially important.

The instrumental variables in (8) capture the various institutional regimes regarding ER eligibility that applied in various sub-periods of our observation period. We collect those in a vector, $z$, to make sure that the identification of $\alpha$ is not driven by functional form assumptions. Given proper handling of the insurance endogeneity, and under the linearity assumption of the model, the resulting coefficient of insurance from (9) corresponds to the local average treatment effect.

For reference, we list the six instruments that we may be able to use, depending on length of sample, along with the variable labels employed in our results tables.

- A binary indicator for whether a person of a certain birth year (or age) in a certain year needed to be enrolled in UI for ER eligibility purposes

- In the years 1991 and before: "ER regime < 1992". In Figure 3 this corresponds to the two blue-shaded regions.

- In the years 1992 to 1998: "ER regime 92 - 98". In Figure 3 this corresponds to the two yellow-shaded regions.

- In the years 1999 to 2007: "ER regime 99 - 07". In Figure 3 this corresponds to the three green-shaded regions.

- In the years 2008 and 2009: "ER regime > 2007". In Figure 3 this corresponds to the red region.

- The number of required years for paying ER contribution, effective as of 1999: "\# contr. years".

This is calculated per birth cohort for years 1999 and later, falling into the following colored 
areas of Figure 3: light-blue, light-yellow, three shades of green, orange, and red. Note that the green-gray, light-green, orange and red areas (cohorts 1960 and younger of age 32 and higher, in year 2006 and later) signify additional changes that came about in 2006 when the early retirement entry age was raised to 62 years.

- A binary indicator for the possibility to join the ER system with the prospect of facing reduced benefits later (so-called 'latecomers'), afforded by the 2007/8 reform: "sign up late option". In Figure 3 this corresponds to the light-green area.

When estimating labor market transitions over a period of nearly 30 years, it is important to control for business cycle effects, institutional changes on the labor market and reforms/adjustments of the benefit system. To do this we include a full set of time dummies. Furthermore, the literature has also shown that both age and cohort effects are important factors. The cohort effects are absorbed into the individual fixed effects and we include a fourth-order polynomial in age which should capture smooth age effects. The variation in the instrument used for identification is therefore obtained from the fact that different cohorts face different age-thresholds for the early retirement option. The identification thus comes essentially from interactions between cohort and age.

For the instruments to be valid we need them to be uncorrelated with the error term in the start-up equation. One potential concern could be that the instrument which is generated from the value of the retirement option is correlated with the error term through e.g. preference for leisure. The individual fixed effects approach helps overcoming this problem by accounting for time-invariant preferences. Furthermore, we control for health and demographics (in particular, covariates relating to spouse characteristics) to partly control for the time-varying preferences for leisure. In addition, the retirement decision is quite far in the future (at least 10 years and up to 35 years in the end of the period), which should weaken the correlation.

As this paper is about insurance channels we also want to control for additional ways of selfinsurance that the household has, outside formal insurance markets. One aspect concerns controlling for wealth, that our model suggest might be important anyway. Wealth may directly serve as buffer for temporary shocks (including business failure) and thus provide insurance functions. In addition, those self-employed (men) with a partner (typically wives) may have recourse to informal insurance through 
their partner's labor supply. ${ }^{22}$ Assuming that the wife makes optimal labor supply decisions, she may, to the extent that she earns below her maximal capacity, be in a position to increase her labor supply in the event of her husband's firm failing or for some reason generating sub-optimal incomes. This view requires very high labor market flexibility in terms of job mobility and hours choice, as is actually the case in Denmark.

We construct a measure of the unused earnings capacity (or remaining labor supply flexibility) by estimating auxiliary models from our data on women. As we do not observe hours worked in the data we are unable to calculate the difference between actual and maximal hours worked. However, we can go down a similar avenue for earnings since actual earnings are observed precisely in the data. The maximal earnings that a woman of given characteristics ${ }^{23}$ can generate may be calculated as the upper envelope of earnings of comparable women in the sample. In order to do this, we estimate stochastic frontier models and define maximal predicted earnings as coinciding with the stochastic frontier. The unused earnings capacity is then the difference between the actual earnings and the frontier. ${ }^{24}$ For implementation, we draw a $25 \%$ sample from our data of women in the age range 18-67, and predict earnings conditional on regressor values for the entire population. We can then control for spouse earnings and its insurance effect by including both the frontier (level of earnings) and the unused capacity.

\section{Data and Descriptives}

\subsection{Register Data}

We use comprehensive register data made available by Statistics Denmark to the Center for Applied Microeconometrics (CAM) at the University of Copenhagen. In terms of variables measured, this is one of the world's richest administrative micro data sets. It covers the entire residential population in Denmark, totaling 5.1-5.5m individuals every year. All individuals are followed over time, annually, from 1980 onwards until 2009. Individuals only enter through birth or immigration and only leave through death

\footnotetext{
${ }^{22}$ A strand of literature in labor economics discusses the 'added worker effect' (see, e.g., Juhn and Potter, 2007, for references and recent analysis), where a working spouse's labor supply variation acts as self-insurance mechanism for the household. A recent semi-structural paper discussing consumption insurance in the face of endogenous labor supply decisions within the household is Blundell et al. (2012) who find the household labor supply margin to be an effective self-insurance device.

${ }^{23}$ The regressor list includes functions of age, education, labor market experience, industry, health, region of residence, country or region of origin, marital status, number of children by age, birth cohort, and time.

${ }^{24}$ In terms of stochastic frontier models, the unused capacity corresponds to the technical inefficiency parameter.
} 
or emigration. In addition to population, tax and benefits register information on individuals, we also use data from linked employer-employee registers, and from linked VAT registers. We exploit such information when assessing the performance of young firms some years after start-up. Profit (and related) measures are available from 1987 through 2009, sales and VAT information are available from 1990 through 2007.

Labor market status is recorded in calendar week 48 (late November) of any given year. Individuals are classified self-employed according to their main economic activity in that particular week. To be specific, the self-employed include those that are employers but also those without employees, those that assist as spouses, and those that are VAT registered. If a person both has a wage earner job and runs his own business the status is determined by the main activity in week 48 . There is a small group of people that are classified as self-employed but also receive wage earnings (and reverse). ${ }^{25}$

We restrict the data according to a few observable variables, in order to reduce heterogeneity. First, we only consider Denmark-born males with Danish citizenship. Second, we restrict attention to the age group of 25-59 year olds, since we are primarily interested in individuals choosing UI fund membership and occupation before actually exiting into early retirement. We exclude all individuals that in the period 1980-2009 have been working in the agricultural sector, either as wage earners or self-employed. Sectoral change strongly affected employment opportunities for these people.

This base data set contains $1.9 \mathrm{~m}$ persons who are followed over up to 30 years, totaling $30 \mathrm{~m}$ observations. For estimation purposes, we also condition on being wage earners in period $t-1$ and not having had a spell of unemployment during $t-1$. We only consider transitions into self-employment as opposed to staying wage earners. We retain a total of $19 \mathrm{~m}$ observations from $1.6 \mathrm{~m}$ distinct individuals.

\subsection{Self-employment and Unemployment Insurance}

Table 1 shows labor market status over time. We see that the fraction of self-employed has declined over TAвLE 1 the period, starting from about 10 percent in 1980 , moving down to 6.8 percent in 2009 . The average was about 8 percent for the whole period. In the period about 83 percent are wage-earners. The remaining 9 percent are either unemployed or out of the labor force. The fraction of non-employment reflects to

\footnotetext{
${ }^{25}$ In our base data set, over the span of 30 years, one third of individuals ever received self-employment income and wage income, but typically not simultaneously. The average share of self-employment income in total income, per individual and year, is about $14 \%$.
} 
a large extent the business cycle with high levels of unemployment in the beginning of the 1980s and 1990 s, and recently in $2008 / 9$. The table also shows that wage employed are more likely to be insured than the self-employed or the unemployed (the latter group includes individuals out of the labor force). The total number of observations is increasing over the period, reflecting population and labor market growth.

Table 2 shows the transitions into and out of self-employment. On average, 1 percent of wage taвLE 2 employed become self-employed in a year, while 3 percent of unemployed start up. 8 percent of selfemployed leave between years to become employees, 3-4 percent become unemployed. The decreasing stock of self-employed suggests that average exit is larger than average entry. Exit rates in particular are sensitive to changes in overall economic conditions (entry rates not much); recessions drive selfemployed out of business.

Now we turn to investigate the unemployment insurance status. Empirical investigations show that changes in UI status are driven by entries rather than exits. Therefore we focus on the entry probability. In Table 3 we display the probability for non-UI fund members to sign up, focusing on the regime change of the 1992 reform. This shows that the entry probability among non-member wage-earners is about 9 percent, except in the last year before the threshold age is reached. In that last year the probability is 22 percent. Similar patterns are found for the self-employed, but not for the unemployed. The incentive to join the insurance system is strongly affected by the changed eligibility criteria.

Table 4 finally shows a cross tabulation of insurance status (in year $t-1$ ) and self-employment start- TaвLE 4 up (year $t$ ) as measured in our estimation sample (which conditions on being a worker in period $t-1$ ). In our sample about $80 \%$ are insured. The insured have a probability of $0.8 \%$ to start up, the uninsured are more likely to become entrepreneurs at almost twice that rate $(1.5 \%)$. The average transition rate is just short of $1 \%$. We shall argue in the next sub-section that the raw difference of -0.7 percentage points between the insured and the uninsured has no causal interpretation.

To illustrate the impact of the instruments we focus on the cohorts born 1931-1942, who had to sign up for the UI fund no later than age 50 to become eligible for early retirement from age 60. We select individuals who are wage earners at age 49, and group them according to their membership status at ages 49 and 50, resulting in four groups. In Table 5 we show the start-up probability per group. The Taвle 5 first two columns refer to those who are not member at age 49 and are therefore (mainly) affected by 
the instrument. If we compare the first group that does not react to the incentive with the second group that does react, we see that the latter group has a higher probability of starting as self-employed in the subsequent three years. Those who do not enroll have a start-up probability at the age of 50 of 1.1 percent while those who do enroll have a probability of 1.4 percent. The last two columns are those who are already member at the age of 49 and therefore only marginally affected by the instrument. Among those, the third group constitutes a tiny minority of less than 1 percent that chooses to exit the UI fund. The vast majority are those who remain in the UI fund (the fourth group). They have a substantially lower probability of starting up of 0.6 percent. The Table shows that those (mainly) affected by the instrument have a higher start-up probability (1.2\%) than the average across all groups $(0.8 \%)$. Similar patterns emerge for most other age groups around the threshold age.

\section{Results}

\subsection{Start-Up and Insurance}

To study start-up on the population that is potentially 'at risk' to make a transition from wage-employment into self-employment in year $t$, we trim the data at the first transition, that is, even for those that are repeatedly observed to start up, we keep only the first instance. We keep only uninterrupted series per individual. ${ }^{26}$ There are $16.5 \mathrm{~m}$ observations from $1.6 \mathrm{~m}$ distinct individuals. Of those, we draw a $25 \%$ sample. ${ }^{27}$ The lag structure in the regressor set further reduces the estimation samples slightly. ${ }^{28}$

Table 6 reports coefficient estimates along with associated p-values obtained from fixed effects (FE) regressions, with and without instrumentation. We interpret the coefficient estimates as marginal effects on the probability to start up owing to our interpretation of the model as a linear probability model. The specification controls for a number of important personal or household characteristics, such as age (as a fourth-order polynomial), experience as wage earner (as a third-order polynomial), measures of wealth (net worth in levels and home ownership) and income (wage earnings and sickness benefit receipts), the

\footnotetext{
${ }^{26}$ Reassuringly, the impact of these choices on empirical estimates is not important. For the majority of the individuals we only observe one start-up transition.

${ }^{27}$ This restriction is chosen for computational convenience, but leaves very large samples. Sample size is important because transitions are infrequent, and there is substantial heterogeneity requiring large samples in order to reliably measure responses to policy variation and changes in controls.

${ }^{28}$ The data record wealth as of 1984 , implying the effective observation period is shorter when controlling for wealth.
} 
number of children in the household (by age group), as well as a number of characteristics of the partner of the individual. Sickness benefit receipt doubles as health (illness) measure.

The partner characteristics (apart from a dummy whether or not a partner is present in the household) are age, whether or not UI fund member, whether participating actively in the labor market, and measures of the partner's earnings capacity (see Section 4). In addition to the reported effects, all specifications control for a full set of year dummies, and for comprehensive sets of region and industry dummies. Interesting as those might be, we shall abstract from discussing them for brevity. Details are available upon request. Many of our variables, at least those that might change easily between years and are potentially correlated with the errors, are lagged at least once, if not twice. By using such predetermined values we mitigate remaining concerns about endogeneity associated with some of the regressors, in particular wealth and income.

We start the discussion of our empirical estimates with results from an uninstrumented model ignoring potential endogeneity of the insurance choice. The first set of columns in Table 6 shows a negative coefficient of $0.05 \%$ on the insurance dummy. It is small in size compared to the raw correlations (see Section 5). The estimate suggests that the raw data difference of -0.7 percentage points (Table 4) is overstated by the impact of observed and unobserved heterogeneity; the insured and uninsured differ in important dimensions.

The age polynomial, with all terms significant, suggests a positive and only slightly curved age pattern in the probability to start up. The experience polynomial displays a negative, countervailing effect in time spent as wage recipient. We keep the rest of the discussion somewhat short as the present model is not the main specification of interest: positive coefficients are estimated for wage earnings and home ownership, as well as for sickness benefit receipt. Demographics including spouse characteristics appear not to matter much, as their marginal effects are very small or insignificant.

As detailed, we have reasons to believe that modeling the insurance choice as endogenous to the self-employment transition decision is important. The first and second stage of the instrumented model are displayed in the second and third set of columns in Table 6. We use all of our six instruments discussed in Section 4. Each instrument is statistically significant, and the $F$-test on joint significance shows that they are important determinants of the insurance choice.

Selection into insurance is strongly impacted by the first age threshold applying in the pre-1992 
period, as the first of our instrumental variables suggests. The marginal effect is 5.3 percentage points. In the period after the 1992 reform and until the 1999 reform the age threshold increases the probability of insurance enrollment by $6.0 \%$. In the regime of the 1999 reform the impact of the age threshold has decreased to 3.5 percentage points and in the last period from the 2007/8 reform onward the effect of the age threshold is 2.1 percentage points. Those results confirm that the effect of the retirement option has been weakened over the entire period, with fewer individuals reacting to the incentive. This is consistent with the fact that early retirement has been made less beneficial by the reforms implemented over the period. There is a small effect of the number of contribution years, i.e., the minimum number of years during which the enrollee has to pay ER contributions (as introduced in 1999) in order to be ER eligible from age 60 (62) on. This is captured by our fifth instrument. The effect is positive. A possible explanation for the sign is a contemporaneous reduction in the UI insurance fee. The last of our instruments also has a positive effect. It becomes relevant with the 2007/8 reform and allows those that otherwise 'missed the deadline' (latecomers) to still sign up for the ER program at reduced future benefits. It has an effect of yet another 2 percent insurance membership. All in all, ER incentives are instrumental in pulling individuals into UI.

The insurance decision is also determined by the other regressors we control for. With few exceptions, all of the displayed coefficient estimates have p-values below $0.5 \%$. The age pattern in insurance is monotonically falling. Recall that we control for year dummies and capture cohort effects through the FE. Experience is positive and near-linear in the 0-20 years range. Experience will proxy for life-cycle wage profiles, and even lagged wage levels have a positive effect on insurance. Our theoretical model is unable to make sharp predictions about the effect of wealth. Empirically, wealth effects, measured through both net worth levels and home ownership, point in opposite directions. Net worth has a negative impact, home ownership a positive, suggesting that the effect of financial wealth, which fulfills a self-insurance and liquidity function, dominates the measured wealth effect on insurance. In that light, the coefficient possibly reflects substitutability between insurance channels. Similar remarks apply to some of the spouse variables that we include, in particular whether the partner works, and what her level of earnings is (measured by the earnings frontier). The unused earnings capacity also is significantly negative in the insurance equation, as expected under insurance substitutability.

Turning now to the self-employment transition equation reveals a significant and positive causal 
effect of insurance on start-up. This finding is in line with our simple economic model. The magnitude is substantial with 1.8 percentage points, compared to a baseline average transition rate of $1 \%$ and $0.8 \%$ for the insured in the raw data. If we compare our estimate to the entries in the first two columns of Table 5 at the first year after the relevant age threshold, we see that our heterogeneity-corrected local average treatment effect (LATE) estimates point in the same direction. Bear in mind that numbers in Table 5 refer to a more specific base sample (cohorts 1931-1942 around age 50), than that underlying Table 6.

The fact that the conclusions are very different from the uninstrumented and unconditional cases shows that not only heterogeneity but also endogeneity matters. Apparently there are factors that determine both insurance choice and start-up, unaccounted for in the regressor set and the FE, that lead to less insurance and more entrepreneurship. ${ }^{29}$ Many of the other effects that we measure in this equation are similar to the uninstrumented case, in terms of sign, significance level and magnitude, so we do not discuss them again.

With a LATE in hand, we cannot directly quantify the total effect of UI on start-up-after all, access to the UI system as such was not modified during the period. Instead, the LATE is only identified from the individuals who react to the retirement incentive. However, we can gauge the total effect of the retirement incentive from a reduced form estimation, where we study the impact of the reform indicators on the start-up outcome, without mediation through insurance. The reduced form estimates are displayed in the last set of columns of Table 6. They suggest a total of 8,705 self-employed induced through the retirement incentive, representing nearly $5 \%$ of the total of start-ups. This estimate is a lower bound as individuals may have decided to start up while insured without us seeing them triggered to do so. ${ }^{30}$

\subsection{Sensitivity Checks}

The main finding of a 1.8 percentage point causal effect of insurance on start-up in Table 6 is very robust. We display in Table 7 results from selected sensitivity checks that subject the baseline set-up to major TAвLE 7 modifications.

\footnotetext{
${ }^{29}$ Candidates are individual risk of unemployment, the quality of the business idea, and health shocks.

${ }^{30}$ The figure of induced self-employed is obtained from multiplying the estimated reduced form coefficients per ER regime with the number of workers per year (as in Table 1, roughly $1 \mathrm{~m}$ per year) and adding the resulting numbers. The figure of total start-ups is observed in the data, Table 4.
} 
We start with a brief look at a random effects (RE) model. The specification is enriched, compared to the FE baseline, with controlling for a restricted set of cohort dummies, and the level of education (in years). Year of birth, and effectively education, would otherwise drop out of a FE specification. The estimated coefficient when insurance endogeneity is taken into account (line 1 of the Table) is nearly unchanged compared to the FE baseline result. This finding is reassuring, as the FE needs 2 observations per individual, and hence will disregard those individuals that happen to transition already in the first year of being observed in our sample. (Uninstrumented RE models again produce a negative coefficient on insurance.) A possible concern about the validity of the RE is a violation of the assumption that individual effects are uncorrelated with regressors and instruments. We can mitigate this by conditioning on time-averaged values of (most) time-varying regressors (Chamberlain-Mundlak approach; we do not time-average year, industry, and region dummies). Line 2 suggests the coefficient of interest drops to 1.2 percentage points, but stays significantly positive. We continue with FE specifications for simplicity.

Our identification comes from variation over and above the age/cohort and year patterns that are detectable in the data. We thus might also want to check robustness with respect to alternative specifications in the pure age and time dimensions. One standard and parsimonious alternative way of modeling time effects is by controlling for aggregate shocks tied to observable macro variation. We can control simultaneously for the regional rate of unemployment, the overall bankruptcy rate, and the real per capital GDP growth rate (line 3). The coefficient on the UI fund membership drops to 0.7 percentage points. This is a large change. We believe, therefore that the additional flexibility afforded by our year dummies approach in the baseline is a necessity. In particular, it will account for, e.g., changes in UI benefit levels and duration. Turning to age effects, line 4 deviates from the baseline by reducing the age polynomial to order 3; line 5 instead relies on age dummies (subject to restrictions). The change in the order of the polynomial appears to have a larger effect on the insurance coefficient $(0.013)$ than the non-parametric modeling through dummies (0.016). Either way, these deviations stay reassuringly close to the baseline.

Line 6 presents results from a major change to the regressor list. This simplest specification relies exclusively on variation in age and time and ignores all other time-varying regressors. The immediate effect is that the sample becomes larger as we do not lose observations due to lagged regressor values. ${ }^{31}$ In line 6, we use age dummies next to year dummies. The model is worth considering because it makes

\footnotetext{
${ }^{31}$ In addition, wealth measures had restricted the sample size in the baseline, see note 28.
} 
the weakest assumptions on the unobservables and keeps the functional flexibility in the conditioning set. It falls into the class of models considered by Blundell and Powell (2003) to non-parametrically identify the impact of discrete endogenous variables with discrete instruments (also see Appendix A in Ejrnæs and Hochguertel (2013)). The fact that this lowers the insurance coefficient (to 1.0 percentage points) suggests that the time-varying heterogeneity otherwise captured by the omitted regressors is of importance to characterize the pools of insurees and would-be entrepreneurs.

When we remove both measures of wealth (both the homeownership dummy and the continuous net worth measure, line 7), we see one of the larger changes as the estimate drops to half its baseline value. Part of the explanation lies in homeownership being strongly correlated with self-employment and insurance, part of the explanation may have to do with the fact that both wealth measures restrict the effective sample period, see note 28. Just removing net worth (while keeping home ownership) does nothing (not shown).

We have gone through many other functional form changes (for instance for income or wealth variables) or additions to the regressor list (e.g., controlling for firm characteristics such as number of employees, number of full-time equivalent workers, ownership type, number of establishments). While some of them are correlated in intuitive ways with self-employment start-up or insurance choice, we do not display nor discuss in detail. In all cases, the coefficient of interest robustly stays in the vicinity of the baseline value.

Line 9 changes perspective and redefines the self-employment dummy purely on the basis of incomes. We flag as self-employed those that earn $62.5 \%$ or more of their income in a given year from self-employment activity. Since self-employment income is negative in about $1 / 4$ of all cases, we first transform it into absolute values before calculating the self-employment income share, in order to avoid this share to fall outside the $[0,1]$ range. The chosen threshold value of $62.5 \%$ reflects to first approximation the fact that self-employed may gain higher incomes simply by working longer hours. The coefficient on being UI insured stays, remarkably, unchanged (0.019). Reducing the income-share threshold to 50 per cent only leads to a slightly larger coefficient (not shown).

Lines 9 and 10 exclude workers in firms that close down, following definitions in Browning and Heinesen (2012). The reason for doing so is to check to what extent the effect we measure is influenced by people that are about to lose their jobs and act by enrolling in UI and/or becoming self-employed. 
The data allow determining the year of closure of an establishment, and Browning and Heinesen (2012) argue that corrections should be made for absorptions of establishments into an existing firm (mergers), and that economic closure (downsizing) may anticipate formal closure. Line 10 uses a wider but related definition allowing for significant non-closure layoffs as well. ${ }^{32}$ In neither case do we find a result that deviates from the baseline, suggesting that layoffs or closures do not drive our main result, and we measure an effect of UI on voluntary employment changes.

The final variation (line 11) concerns the number of instruments we use. For instance, we can drop the last two instruments (number of contribution years and sign-up late option) without substantially affecting identification nor the estimate of the coefficient of interest (1.6 percentage points). The main identification comes through the changing threshold ages between cohorts and across years.

\subsection{Heterogeneous Effects}

This subsection presents a number of additional variations in an attempt to say more on which particular sub-groups in the population drive the main estimates. We do so by splitting the samples according to observables. Results are in Table 8.

First we estimate on different time periods: 1980-1998 and 1993-2009 (lines 1a and 1b, respectively). The estimates of the coefficient on the UI fund show an insignificant effect in the early period and a strong positive effect in the later period. Since the effect in the early period is identified from 40 to 50 year olds and the effect of the later period is identified from 32 to 49 year olds, we cannot tell, however, whether the difference is due to age or whether the effect has changed over time.

A second interesting split is by education, where we also find heterogeneous effects of the UI fund (see lines 2a-c). The impact of insurance has a much stronger effect on individuals with intermediate education (mainly vocational training) compared to individuals with low or high education where insignificant effects are found. Third, we compare the effect for married individuals versus single (lines

\footnotetext{
${ }^{32}$ Specifically, Browning and Heinesen (2012) identify the year of (economic) closure of an establishment as the year that registered the highest absolute reduction in the workforce prior to the year of closure as determined by Statistics Denmark. The latter bases their definition on criteria involving identity of owners and employees, address and industry affiliation. Adjustments are being made for absorption of a plant into other establishments (e.g., mergers). See Appendix A in Browning and Heinesen (2012) for details. While we follow their lead closely, we do not have access to exactly the same cut of the data. In our alternative definition (line 10), we also consider large layoffs corresponding to at least $30 \%$ of the workforce and at least 10 employees. Unlike Browning and Heinesen (2012) who consider single-establishment firms, we define those variables at the firm level.
} 
$3 \mathrm{a}$ and $3 \mathrm{~b}$ ) and find UI has a lower effect for married or partnered individuals, again consistent with an insurance effect through the potential of a second earner. Fourth, there appears to be no significant difference in the UI-induced start-up probability when we split by home ownership (conditional on wealth; see lines $4 \mathrm{a}$ and $4 \mathrm{~b}$ ). Fifth, we divide the sample according to whether or not individuals work (as a wage-earner) in an innovative industry, as classified according to OECD (2011) standards. Here we see that whereas the effect of insurance is more important for individuals in non-innovative ('traditional') industries (line 5a) compared to innovative ones (line 5b), even start-up from innovative firms is helped by insurance.

Summarizing our findings, insurance is more important for starting up for certain groups. The estimation on sub-groups indicates that for younger individuals, for those with intermediate education, for those working in traditional (non-innovative) industries, and for those that are not partnered, UI increases the probability of being an entrepreneur. Detailed information on the heterogeneous effects of insurance is important when evaluating the impact of insurance on entrepreneurship.

\subsection{Firm Performance and Insurance}

This paper deviates from the literature on insurance-induced entrepreneurship by actually assessing how the new entrepreneurs fare when they are insured. For our analysis on post-transition outcomes we use, where possible, the entire population of self-employed that started up in year $t$, and perform crosssectional types of analyses. We first have a look at how outcomes correlate with insurance status in the raw data, see Table 9. Around $60 \%$ of those that started in $t$ are not around anymore after three years. TAвцE 9 However, the insured are more likely to survive to at least period $t+3$, with a significant difference of 7 percentage points. Note that survival here means being observed to be self-employed end November of each year in $t+1, t+2$, and $t+3$. Firms of the self-employed are not guaranteed to survive this long, as we do not hold constant a firm identifier.

Conditional on survival to $t+3$, we may also look at other outcomes, partly obtained from linked employer-employee data. The data is available to us for the sub-period 1987-2009. Profits are incomes generated by the entrepreneur (self-employment income) plus retained earnings that are kept in the firm and are not directly available for consumption by the owner. For most firms (median), profits of surviving insured entrepreneurs are higher than the profits of surviving uninsured ones. This is not true 
on average, however, since mean profits of the uninsured are higher. The uninsured are also more likely to incur losses or make zero profit. The difference is 5 percentage points. This indicates that uninsured entrepreneurs have a more dispersed distribution of profits. It is consistent with uninsured entrepreneurs taking more risk and may possibly be explained by lower risk aversion.

We also have access to financial outcome measures from VAT registers (for a shorter time span from 1990 to 2007). We calculate value added as the difference between sales revenues and expenses. Similar to the average profit figures, all of sales revenues, value added, and exports are negatively correlated with insurance.

Small firms quite often only employ their owner and no-one else. Those with employees often employ 10 or fewer workers. Assuming that firms grow over time in both financial terms and in terms of the number of workers, we may measure performance in terms of whether any other workers are being employed (except for the self-employed person himself). We were able to link data with an establishment identifier to the relevant set of individuals for the period from 1990 on. On average, a third of all firms employ any workers three years after start-up. The insured entrepreneurs are 6 percentage points more likely to employ others compared to the uninsured entrepreneurs.

Table 10 shows results of IV regressions for selected performance measures. These are cross- тавце 10 sectional estimates where we cluster on person-ID to take into account that a small fraction of entrepreneurs makes it more than once to our sample of newly started firms. The underlying sample conditions on start-up between years $t-1$ and $t$. We consider the three measures 'survival', 'profits', and 'having employees' (being an employer). All outcome variables are observed at time $t+3$, and for the latter two measures we also condition on survival to $t+3$. We also include years of education, next to comprehensive sets of year, region, industry, and year of birth dummies in the specification. For profits and being an employer, we use all firms that started up and survived, for survival, we use $25 \%$ of start-ups.

For brevity, we only discuss the causal impact of insurance. This parameter is insignificantly different from zero in all models, on survival, profit, and being an employer. This suggests, in combination with the transition results discussed earlier, that while insurance causes start-up, survival probabilities conditional on start-up are unaffected by insurance. There is, however, still a long-term effect of insurance on the number of firms in business: because insurance does not affect the failure rate, in total 
more small firms will exist at any point in time due to insurance. Since the results on profits and being an employer suggest that there is no causal link between insurance and firm outcomes conditional on survival, we interpret the evidence as insurance selecting neither plums nor lemons. Small firms that are being created because their owner receives insurance protection are not in any way different from any other firm.

We support this interpretation with an array of sensitivity checks in Tables 11 and 12. Table 11 focuses on survival and employment, Table 12 on financial outcomes. The first variation in Table 11 Table 11 (line S1) measures the causal impact of the initial insurance choice on survival until $t+5$ (the sample again conditions on entry between $t-1$ and $t$ ). The effect is again not significantly different from zero. Lines S2 and S3 show the uninstrumented equivalents to those in S0 and S1. We find that OLS estimates are significantly positive, for both time horizons. The estimates show that those that are observed to be insured are about 10 percentage points more likely to survive five or at least 3 years than those that are not insured. This might be interpreted as evidence of negative selection into insurance through heterogeneity.

Variation S4 measures whether the self-employed survives to $t+3$ (in the above sense) while not having wage income; we dub those 'full-time' self-employed. This measure thus tries to remove contaminations into the sample by people that partly rely on wage earnings. This changed definition does not affect the conclusion.

Lines S5 and S6 consider the joint probability of starting up and surviving; both estimates are based on panel data models similar to those in Table 6. The effect of insurance on the joint probability is around $2 \%$. The similarity with the start-up models strongly suggests that the main effect is due to insurance impacting on start-up, not on survival.

The second set of results in Table 11 concerns employment outcomes. Some of the variations are very similar to those on survival (in particular E1-E3), and results likewise suggest that there is no impact of insurance on the future probability to create employment. Lines E4 and E5 use an alternative measure of employment: headcounts of workers at a firm measured at the time of record of the matched employer/employee data. This measure may deviate from the one provided by Statistics Denmark for various reasons, but it can be constructed until the beginning of our data in 1980. We gain a couple of years (recall that the estimation sample is limited because of using wealth as a regressor, note 28). 
Line E4 uses the same time window as the baseline, line E5 extends the sample back in time. Variation E4 suggests no difference to the baseline, variation E5 records a lower probability of employing others with earlier data. Recall that in the earlier period the policy change acts on comparatively older workers who may not have the same growth ambitions as younger ones. Finally (line E6) we consider the actual number of employees (based on the same variable that we use in the baseline, E0). Even though we find a large positive and borderline significant effect of insurance, the size may be overstated for the majority of firms because the firm size distribution is heavily skewed.

We further discuss the results on financial outcomes in Table 12. Apart from profits (including тавце 12 retained earnings) we can consider value added, sales and export revenues, business income (excluding retained earnings) and total income (including wage income). We also check on accumulated wealth and its change between years. All IV estimates of the causal effect are statistically zero, and signs point in different directions between specifications (lines F0-F8). We skip a discussion of lines F1-F4. Line F5 attempts to introduce some stability into the profit measure by averaging across years $t+3$ through $t+5$. Conditioning remains on survival as self-employed, this time until $t+5$. Again, the effect of insurance is zero.

Lines F6 through F8 deserve brief comment, as we here do not condition on survival until $t+3$. Self-employment as a labor market status is closely linked to the legal status of the firm. A firm that changes status from unincorporated to incorporated (whether or not going public), will see its owner change from self-employed to non-self-employed. Since changing legal status is often associated with size or growth and success, we might select against the most successful ones if we condition the data on surviving as self-employed (thence unincorporated firm) until $t+3$. Therefore, lines F6-F8 only condition on start-up between $t-1$ and $t$. We then measure success by total income (which, in case of firms that became incorporated, includes the wage earned by the owner, line F6), by total net worth of the owner (line F7), or by the change in net worth between $t-1$ and $t+3$ (line F8). The idea in the latter two variations is that if successful self-employed sell their firm, their private net worth would increase. None of these variations leads to any different conclusions, however.

Corresponding uninstrumented results (lines F10 through F18) suggest clear negative effects. Insured entrepreneurs fare worse in terms of income and profit (although the differences are modest), but better in terms of survival. Again, heterogeneous sorting effects into insurance will play a large role in 
explaining the difference between the IV and the OLS estimates. ${ }^{33}$

Our empirical results are consistent with most of our predictions from the theoretical model. We do find a significant positive causal impact of insurance on the start-up probability. In the absence of direct measures of investments we look at the number of employees and profit as an indicator for investments. We find insignificant causal effects of insurance on the number of employees, profits, and the probability of surviving as an entrepreneur. One remaining explanation is that our performance measures only pick up short run returns of investments due to a relatively limited time horizon of 3 to 5 years.

We close with a short reflection on other work. In a widely cited paper, Kerr and Nanda (2009) investigated the outcomes of US branch banking deregulation on firm start-up and crowding out of incumbent firms. They find that enhanced competition in financial markets led unambiguously to more entry of firms. The story is that debt-financed ventures were generated because access to external finance became easier post-deregulation. They also find, however, that closure rates increased as well, and particularly so among the small, newly created firms. So deregulation was accompanied by increased churning among small entrants. Our results are different, even though, as in Kerr and Nanda (2009), our data is dominated by the smallest of firms. The level-playing field on the insurance margin between wage and self-employed workers, encourages entry without (possibly inefficient) churning.

\section{Conclusions}

The role that insurance provision may play in helping workers to transition into entrepreneurship and start up risky ventures is the focus of a recent strand of literature. Clearly, if new entrepreneurs contribute to technical innovation and economic growth, then protecting them from some of the consequences of that risk may encourage entrepreneurship and hence growth. Available studies to date have centered around two large insurance mechanisms: lenience in bankruptcy regulation (possibility for debt discharge and partial asset retention) and availability of subsidized health insurance. Both are rather indirect ways of insuring entrepreneurial risk taking.

\footnotetext{
${ }^{33}$ We have, in addition to the reported results, analyzed a number of models where we study the effect of insurance on outcomes where outcome measures are not conditional on survival. That means, we have replaced missings with zeros if a firm that started up did not survive until a given horizon. Results of these exercises are available on request. Even though they cannot be summarized succinctly, most results point into the direction that among those that ever started up, insurance is not conducive to better or worse performance (outcome). Often, parameter estimates are drawn towards zero compared to the results reported in our Tables.
} 
We, instead, focus on a more direct way of insuring income shocks through unemployment insurance. The empirical data we use are from Denmark, whose unique institutional setting we exploit to identify the effect of insurance on start-up. Two main features are particular about the Danish case: (i) unemployment insurance is available to all self-employed and workers alike on a voluntary basis, and (ii) an early retirement system is embedded in the UI system that provides additional incentives to sign up for insurance many years before the ER option is actually exercised.

In this study we use a natural experiment to identify the causal effect on insurance. We exploit the fact that ER eligibility criteria give an additional incentive to take up insurance and that these criteria have been changed a number of times during our 30 year period. The ER eligibility reforms have been implemented such that the latest age at which to enroll in UI varies over birth cohort and time. This is particularly important in the present context as both UI enrollment and entrepreneurial start-up are likely to vary over time, age and cohort anyhow. The particular design of the reforms allows us to control for time, cohort and age effects non-parametrically. Making use of such a natural experiment over a long span of time in the particular start-up and insurance setting is the main methodological contribution of this paper to the existing literature.

We find that insurance has a positive causal effect on start-up, after instrumentation for the insurance choice. Not instrumenting leads to a reversed sign, reflecting the unconditional correlations observed in raw data-entrepreneurs are less likely to be insured.

The second main contribution to the existing literature on the insurance/entrepreneurship nexus concerns an in-depth analysis of post-transition performance measures. Using linked employer-employee information, we can use firm characteristics to gauge to what extent the new insurance-induced selfemployed fare better or worse than their uninsured counterparts. We focus on measures three years after the transition into self-employment has been made, and consider outcome measures such as the likelihood of survival, having employees, or the level of profits. Remarkably, we find no evidence that insurance-induced entrepreneurs are of better or of worse quality than others.

What we document in this paper may have important policy implications because our results show that providing unemployment insurance can increase the likelihood that wage-earners establish new firms. ${ }^{34}$ Furthermore, individuals for whom entrepreneurship becomes attractive when insurance is

\footnotetext{
${ }^{34}$ This finding is complementary to Ejrnæs and Hochguertel (2013) who ask to what extent insurance causes moral hazard
} 
available can compete with incumbents as they have the same survival rates and growth prospects. This finding is important when evaluating policies promoting entrepreneurship, because it might be very costly both for society and the individual if many unsuccessful entrepreneurs enter self-employment. However, our analysis shows that there may be large differences between counterfactual results as we present them here and raw correlations in the data; policy-makers are ill-advised to base policy prescriptions on simple correlations; after all, people that choose to insure themselves may have characteristics that are negatively correlated with factors that determine entrepreneurial success. Lastly, broadening the entrepreneurship base by encouraging self-employment start-up may help increasing labor market flexibility, which is one way of responding to the macroeconomic challenges of globalization and demographic aging.

among the self-employed, i.e., do those that have signed up for insurance behave differently and, for instance, take less care to avoid failure. Moral hazard explains about $30 \%$ of the overall failure rate. 


\section{References}

Akyol, A. and Athreya, K. B. (2011). Credit and self-employment. Journal of Economic Dynamics and Control, 35:363-385. 5

Alexopoulos, M. and Domowitz, I. (1998). Personal liabilities and bankruptcy reform: An international perspective. International Finance, 1:127-159. 8

Armour, J. and Cumming, D. (2008). Bankruptcy law and entrepreneurship. American Law and Economics Review, 10:303-350. 8

Berkowitz, J. and White, M. J. (2004). Bankruptcy and small firms' access to credit. RAND Journal of Economics, 35:69-84. 5

Bertrand, M. and Kramarz, F. (2002). Does entry regulation hinder job creation? Evidence from the French retail industry. Quarterly Journal of Economics, 117(4):1369-1413. 7

Blundell, R., Pistaferri, L., and Saporta-Eksten, I. (2012). Consumption inequality and family labor supply. Working paper no. 18445, Cambridge, Mass.: NBER. 23

Blundell, R. and Powell, J. (2003). Endogeneity in nonparametric and semiparametric regression models. In Dewatripont, M., Hansen, L. P., and Turnovsky, S. J., editors, Advances in Economics and Econometrics: Theory and Applications, Eighth World Congress, Volume II, chapter 8, pages 312357. Cambridge University Press, Cambridge. 31

Branstetter, L., Lima, F., Taylor, L. J., and Venâncio, A. (2013). Do entry regulations deter entrepreneurship and job creation? Evidence from recent reforms in Portugal. Economic Journal, forthcoming. 7

Browning, M. and Heinesen, E. (2012). Effect of job loss due to plant closure on mortality and hospitalization. Journal of Health Economics, 31:599-616. 31, 32, 52

Caliendo, M., Fossen, F., and Kritikos, A. (2009). Risk attitudes of nascent entrepreneurs: new evidence from an experimentally-validated survey. Small Business Economics, 32:153-167. 14 
Cerqueiro, G. and Penas, M. F. (2011). How does personal bankruptcy law affect start-ups? Discussion paper no. 2011-029, European Banking Center. 7

DeCicca, P. (2010). Health insurance availability and entrepreneurship. Working paper no. 10-167., Kalamazoo, MI: W.E. Upjohn Institute for Employment Research. 6

Dohmen, T., Falk, A., Huffman, D., Sunde, U., Schupp, J., and Wagner, G. G. (2011). Individual risk attitudes: measurement, determinants, and behavioral consequences. Journal of the European Economic Association, 9(3):522-550. 14

Economic Council (2011). The Danish economy, Spring 2011. In Danish: Dansk Økonomi, forår 2011. Report, Copenhagen: Det Økonomiske Råd. 7

Ejrnæs, M. and Hochguertel, S. (2013). Is business failure due to lack of effort? Empirical evidence from a large administrative sample. Economic Journal, 123(571):791-830. 7, 9, 19, 31, 38

Ekelund, J., Johansson, E., Järvelin, M.-R., and Lichtermann, D. (2005). Self-employment and risk aversion—evidence from psychological test data. Labour Economics, 12:649-659. 14

European Parliament (2014). Social protection for all, including self-employed workers. Technical Report T7-0014/2014, Brussels: European Parliament, Committee on Employment and Social Affairs. 1

Evans, D. S. and Jovanovich, B. (1989). An estimated model of entrepreneurial choice under liquidity constraints. Journal of Political Economy, 97:808-827. 14

Fairlie, R. W., Kapur, K., and Gates, S. (2011). Is employer-based health insurance a barrier to entrepreneurship? Journal of Health Economics, 30:146-162. 6

Fan, W. and White, M. J. (2003). Personal bankruptcy and the level of entrepreneurial activity. Journal of Law and Economics, 45:543-567. 5

Giannetti, M. and Joensen, J. S. (2013). Unemployment insurance and entrepreneurship: Evidence from a natural experiment. Conference presentation, Tinbergen Institute. 5 
Gruber, J. and Poterba, J. (1994). Tax incentives and the decision to purchase health insurance: Evidence from the self-employed. Quarterly Journal of Economics, 109:701-733. 5

Gumus, G. and Regan, T. L. (2009). Self-employment and the role of health insurance. Discussion paper no. 3952, Bonn: Institute for the Study of Labor (IZA). 5

Heim, B. T. and Lurie, I. Z. (2010). The effect of self-employed health insurance subsidies on selfemployment. Journal of Public Economics, 94:995-1007. 6

Heim, B. T. and Lurie, I. Z. (2013). The impact of insurance subsidies on self-employment: do state non-group health insurance regulations matter? Contemporary Economic Policy, 31(1):94-109. 6

Hombert, J., Schoar, A., Sraer, D., and Thesmar, D. (2013). Can unemployment insurance spur entrepreneurial activity? Evidence from France. Unpublished, HEC Paris. 4, 7

ILO (1955). Unemployment insurance schemes. Studies and Reports, New Series, No. 42, Geneva: International Labour Office. 1

Jia, Y. (2011). The impact of personal bankruptcy law on entrepreneurship. Unpublished, University of Prince Edward Island, Canada. 5

Juhn, C. and Potter, S. (2007). Is there still an added worker effect? Working paper, University of Houston. 23

Kanbur, S. M. (1979). Of risk taking and the personal distribution of income. Journal of Political Economy, 87:760-797. 14

Kerr, W. and Nanda, R. (2009). Democratizing entry: banking deregulations, financing constraints, and entrepreneurship. Journal of Financial Economics, 94:124-149. 7, 37

Kihlstrom, R. E. and Laffont, J.-J. (1979). A general equilibrium entrepreneurial theory of firm formation based on risk aversion. Journal of Political Economy, 87:719-749. 14

Lee, S.-H., Yamakawa, Y., Peng, M. W., and Barney, J. B. (2011). How do bankruptcy laws affect entrepreneurship development around the world? Journal of Business Venturing, 26:505-520. 5 
Lentz, R. (2009). Optimal unemployment insurance in an estimated job search model with savings. Review of Economic Dynamics, 12:37-57. 9

Madrian, B. (1994). Employment-based health insurance and job mobility: Is there evidence of a joblock? Quarterly Journal of Economics, 109:27-54. 5

Meh, C. A. and Terajima, Y. (2008). Unsecured debt, consumer bankruptcy, and small business. Working paper \#2008-5, Bank of Canada. 5

OECD (2006). Denmark. Economic Survey, Paris: Organisation for Economic Co-operation and Development. 13

OECD (2011). OECD Science, Technology and Industry Scoreboard 2011: Innovation and Growth in Knowledge Economies. Organisation for Economic Co-operation and Development, OECD Publishing, Paris. 33, 53

Paik, Y. (2013). Bankruptcy Reform Act of 2005 and entrepreneurial activity. Journal of Economics and Management Strategy, 22:259-280. 5

Parsons, D. O., Tranæs, T., and Lilleør, H. B. (2003). Voluntary public unemployment insurance. Unpublished, George Washington University. 8, 10

Pedersen, H. H. and Huulgaard, A., editors (2007). Arbejdslфshedsforsikringsloven 1907-2007. Arbejdsdirektoratet, Copenhagen. 7

Primo, D. M. and Green, W. S. (2011). Bankruptcy law and entrepreneurship. Entrepreneurship Research Journal, 1:art. 5.5

Røed, K. and Skogstrøm, J. F. (2013). Unemployment insurance and entrepreneurship. Discussion paper no. 7121, IZA Institute for the Study of Labor. 4, 7

Schoukens, P. (2000). Comparison of the social security law for self-employed persons in the member states of the European Union. In Pieters, D., editor, Changing Work Patterns and Social Security. EISS Yearbook 1999, pages 63-98. Kluwer Law International, London. 8 
Statistics Denmark (2009). Nyt fra Danmarks Statistik: Erhvervsdemografi. News brief, Copenhagen: Danmarks Statistik. 8

Statistics Denmark (2010). Nyt fra Danmarks Statistik: Konkurser. News brief, Copenhagen: Danmarks Statistik. 8

Velamuri, M. (2012). Taxes, health insurance and women's self-employment. Contemporary Economic Policy, 30(2):162-177. 5

Vereshchagina, G. and Hopenhayn, H. A. (2009). Risk taking by entrepreneurs. American Economic Review, 99:1808-1830. 14 


\section{Appendix A Figures and Tables}

\section{Appendix A.1 Figures}

Figure 1: Unemployment Insurance Incidence, Men Born 1945

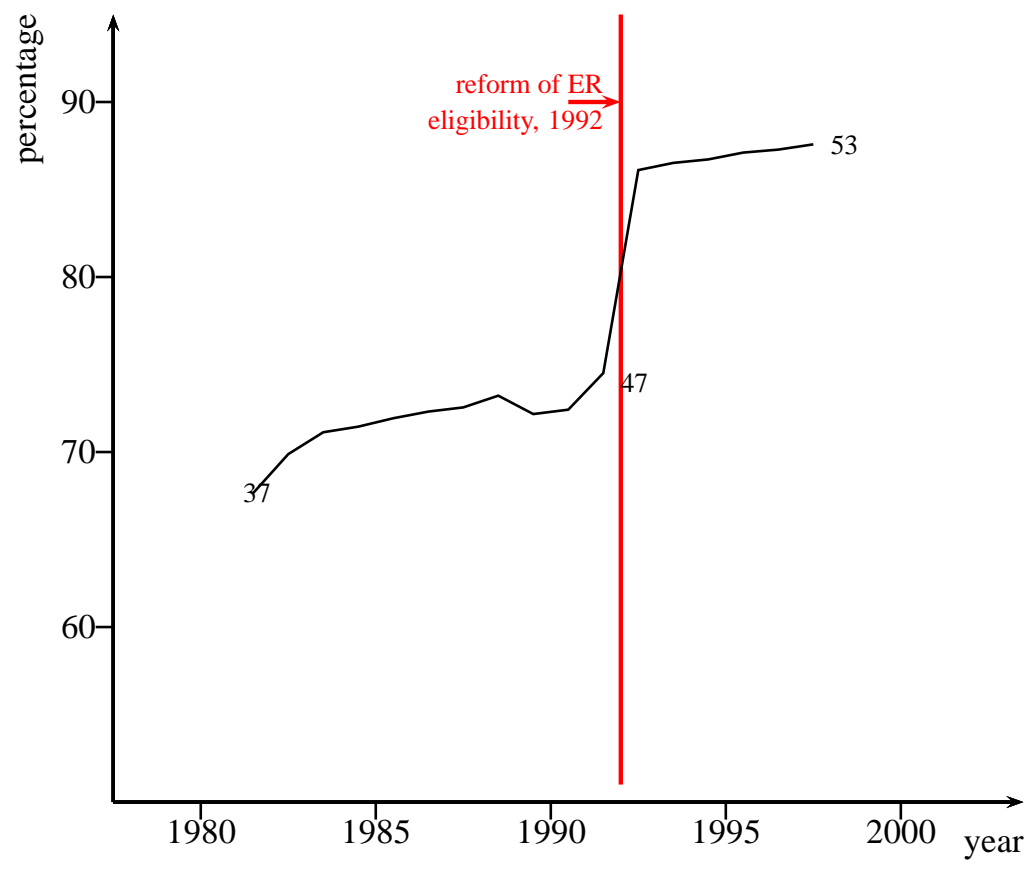


Figure 2: UI Entry Rates, by Year-of-Birth Cohort and Year ('Heat Map')

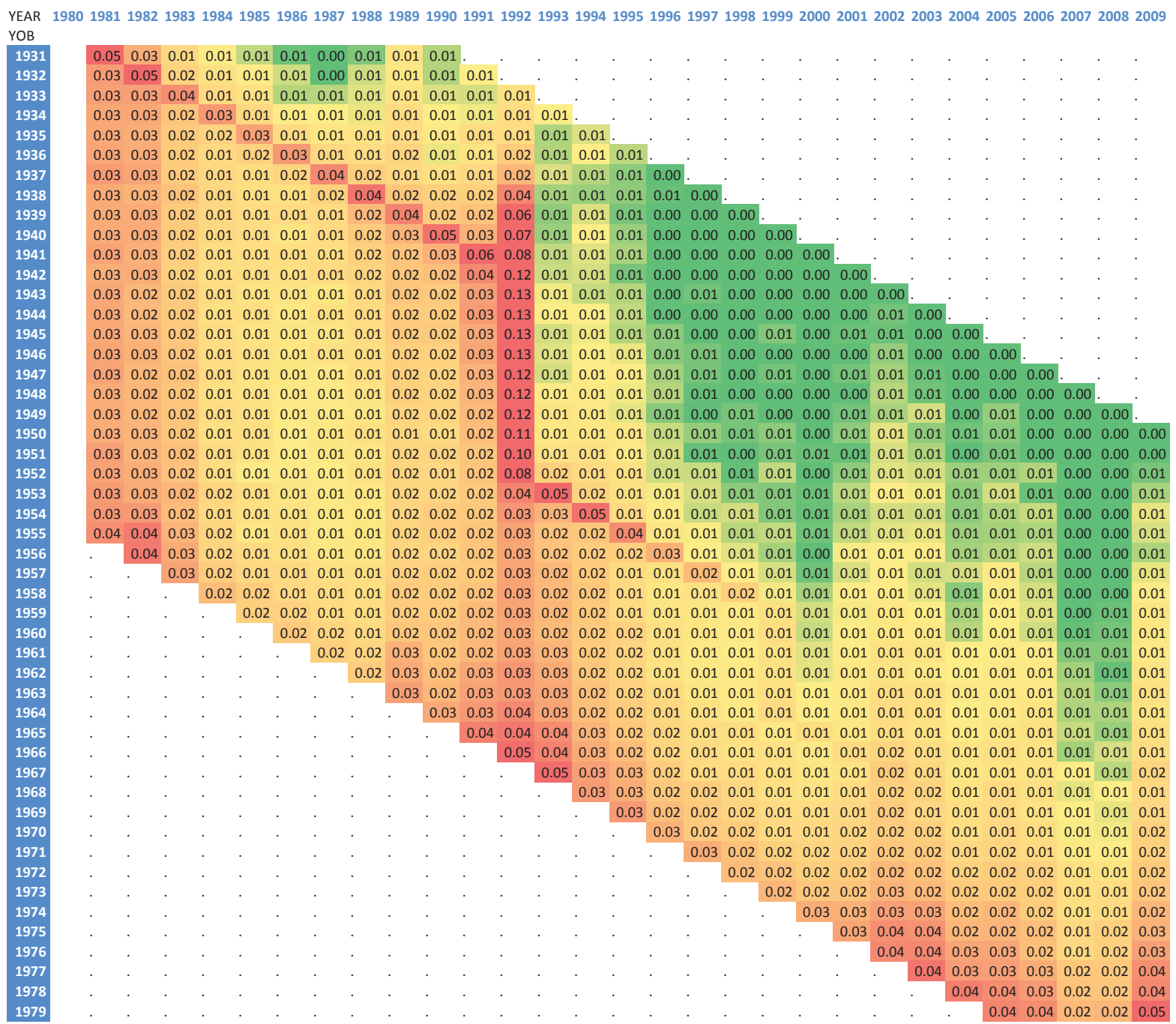

Note: Map shows cohort-year specific entry rates into UI as observed in the data (working males). Colored area corresponds to data restriction (ages 25-59). Green: below-average entry rates, red: above-average. 
Figure 3: Regimes of Early Retirement Rules, by Year-of-Birth Cohort and Year

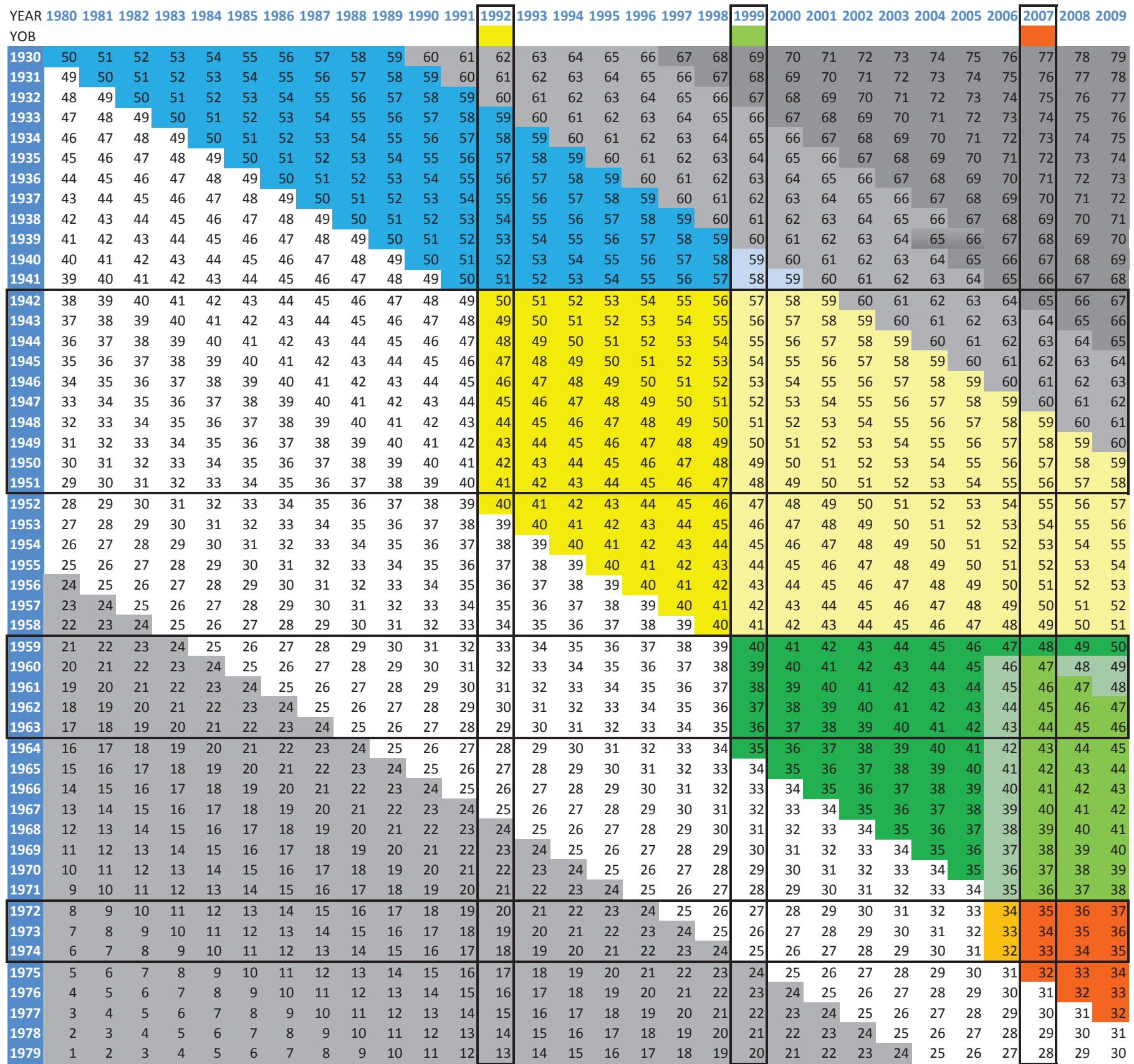

LEGEND

sample exclusions

not in sample (likely not yet participating in the labor market or potentially eligible for early retirement) not in sample, eligible for old-age pension

minimum required insurance ages to qualify for early retirement at the earliest age (60-62 depending on cohort and year) initial situation, valid from 1980

those unaffected by the 1992 reform, but affected by the contribution requirements from 1999 on those affected by the 1992 reform

those affected by the 1992 reform, and by the contribution requirements from 1999 on

those affected by the 1999 reform, and those affected by the "sign-up-late"option from the 2007/8 reform those affected by the $2007 / 8$ reform

those affected by the 2006 change of early retirement age of up to 62 (increase in contribution years) instrument sets

ER regime $<1992$

ER regime $92-98$

ER regime 99-06

ER regime $>2006$

\# contr.years

sign up late option 
Figure 4: Optimal Investment [1] and Expected Utility [r] for Entrepreneurs as Functions of Initial Wealth, by Insurance Status
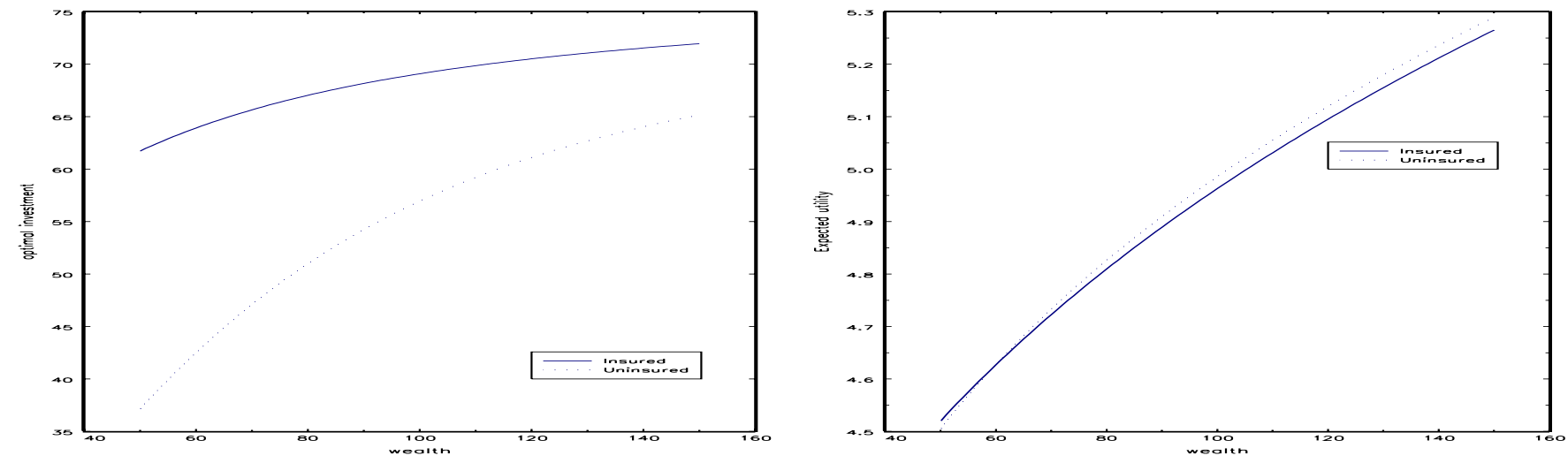

Figure 5: Optimal Investment [1] and Expected Utility [r] for Entrepreneurs as Functions of Ability, by Insurance Status
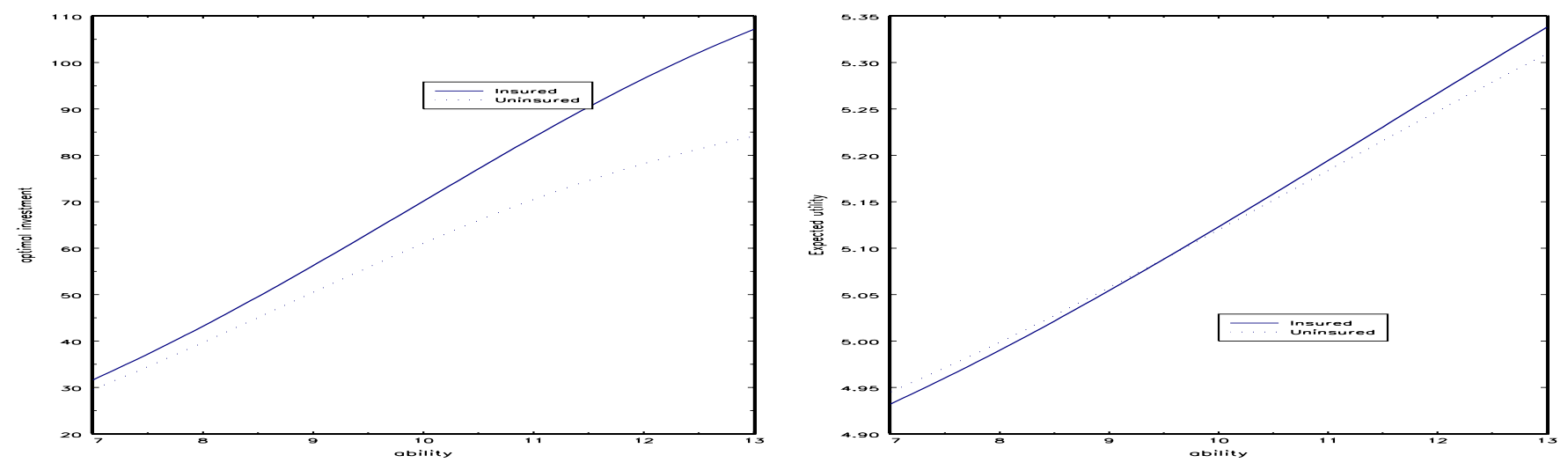

Figure 6: Occupational Choice as a Function of Wealth and Ability, by Insurance Status [1/r]
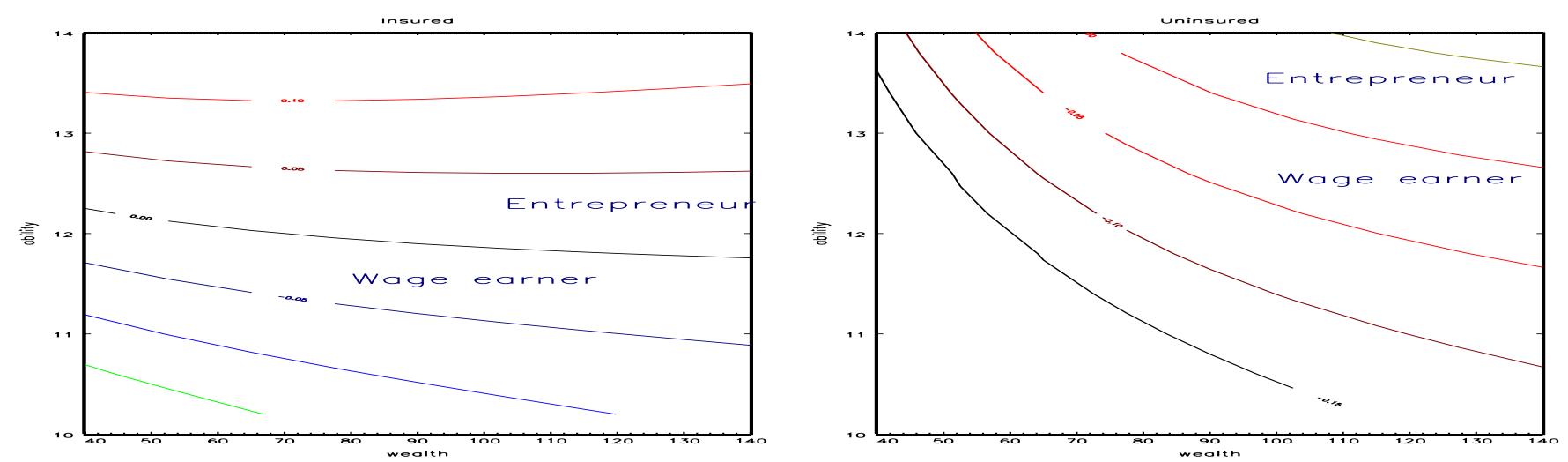


\section{Appendix A.2 Tables}

Table 1: Labor Market Status, Selected Years (Per Cent)

\begin{tabular}{rrrrr}
\hline \hline year & SE & WE & UE & Totals \\
\hline 1980 & 10.25 & 79.97 & 9.78 & 934,155 \\
1985 & 8.89 & 83.43 & 7.68 & 953,843 \\
1990 & 8.12 & 81.20 & 10.67 & 985,972 \\
1995 & 7.81 & 82.59 & 9.60 & $1,009,485$ \\
2000 & 7.35 & 85.26 & 7.39 & $1,028,332$ \\
2005 & 6.46 & 85.57 & 7.98 & 995,255 \\
2009 & 6.81 & 81.10 & 12.09 & 952,401 \\
\hline Total & 7.91 & 82.83 & 9.26 & $29,611,937$ \\
per cent & & & & \\
insured & 61.17 & 82.18 & 61.94 & 78.65 \\
\hline \hline
\end{tabular}

Note: Population of Denmark-born Danish prime aged (2559) men never in agriculture by labor market status. SE: Selfemployed, WE: wage employed, UE: unemployed.

Table 2: Transitions Into and Out of Self-employment (Selected Years)

\begin{tabular}{lrrrrrr}
\hline \hline & \multicolumn{2}{c}{ entry } & \multicolumn{2}{c}{ exit } & stock & GDP \\
from/to & WE & UE & WE & UE & SE & growth \\
\hline $1980 / 2009$ & 0.95 & 3.14 & 8.47 & 3.58 & 7.91 & 1.8 \\
\hline $1980 / 1981$ & 0.92 & 2.75 & 6.80 & 3.67 & 10.25 & -0.9 \\
$1985 / 1986$ & 1.13 & 3.46 & 6.95 & 2.11 & 8.89 & 4.9 \\
$1990 / 1991$ & 1.05 & 5.64 & 8.32 & 3.97 & 8.12 & 1.3 \\
$1995 / 1996$ & 0.87 & 3.63 & 7.52 & 3.39 & 7.81 & 2.8 \\
$2000 / 2001$ & 0.90 & 3.27 & 9.59 & 2.31 & 7.35 & 0.7 \\
$2005 / 2006$ & 0.90 & 3.16 & 9.84 & 2.50 & 6.46 & 3.4 \\
$2008 / 2009$ & 0.89 & 3.07 & 9.88 & 4.64 & 6.97 & -5.7 \\
\hline \% correl. w. & & & & & & \\
GDP growth & -14.38 & -3.86 & -33.63 & -36.80 & 15.24 & \\
\hline \hline
\end{tabular}

Note: Real annual GDP growth per capita from Eurostat, series nama_gdp_k, PCH_PRE. Displayed correlation is calculated using all years in the period 1980-2009. Also see notes to Table 1. 
Table 3: Joining UI Fund by Labor Market Status and Force of ER Incentive, 1992 Reform

\begin{tabular}{lrrr}
\hline \hline \multirow{2}{*}{$\begin{array}{l}\text { UI fund entry } \\
\text { between }\end{array}$} & \multicolumn{3}{c}{ labor market status, year $t-1$} \\
\cline { 2 - 4 }$t-1$ and $t$ & $\begin{array}{r}\text { self- } \\
\text { employed }\end{array}$ & $\begin{array}{r}\text { wage } \\
\text { earner }\end{array}$ & $\begin{array}{r}\text { unem- } \\
\text { ployed }\end{array}$ \\
\hline all ages before & & & \\
threshold age & & & 92.54 \\
\hline \multicolumn{1}{c}{ no } & 91.00 & 90.99 & 7.46 \\
\multicolumn{1}{c}{ yes } & 9.00 & 9.01 &
\end{tabular}

last year before

threshold age

$\begin{array}{lrrr}\text { no } & 75.58 & 78.20 & 93.75 \\ \text { yes } & 24.42 & 21.80 & 6.25\end{array}$

ages larger than

threshold age

\begin{tabular}{crrr}
\hline no & 92.55 & 93.42 & 96.15 \\
yes & 7.45 & 6.58 & 3.85 \\
\hline \hline
\end{tabular}

Note: column percentages. Population: not UI-fund member in $t-1$ (else as in Table 1). Threshold age is the age at which an individual should ultimately sign up for UI in order to be ER eligible, see Figure 3.

Table 4: Self-employment Entry by Insurance Status, Population of Wage Employed

\begin{tabular}{lrrr}
\hline \hline & UI fund member $(t-1)$ & Total \\
Self-employed $(t)$ & no & yes & \\
\hline no & $3,748,876$ & $15,173,588$ & $18,922,464$ \\
& 98.46 & 99.21 & 99.06 \\
yes & 58,649 & 120,932 & 179,581 \\
& 1.54 & 0.79 & 0.94 \\
\hline total & $3,807,525$ & $15,294,520$ & $19,102,045$ \\
\hline \hline
\end{tabular}

Note: Absolute numbers and column percentages.

Table 5: Probability to Start Up Around Threshold Age, Cohorts 1931-1942

\begin{tabular}{lcccc}
\hline \hline & $\begin{array}{c}\text { Never } \\
\text { Enrolled }\end{array}$ & Enrollment & Withdrawal & $\begin{array}{c}\text { Always } \\
\text { Enrolled }\end{array}$ \\
\hline UI fund age 49 & No & No & Yes & Yes \\
UI fund age 50 & No & Yes & No & Yes \\
\hline SE at age 50 (\%) & 1.1 & 1.5 & 2.2 & 0.7 \\
SE at age 51 (\%) & 1.6 & 2.2 & 3.1 & 1.1 \\
SE at age 52 (\%) & 2.2 & 2.9 & 4.0 & 1.5 \\
\hline$N$ & 44,649 & 9,772 & 1,035 & 133,695 \\
\hline \hline
\end{tabular}

Population: see note to Table 1, and born in 1931-1942, at age 49 or 50. 
Table 6: Probability to Start Up: Linear Fixed Effects Models

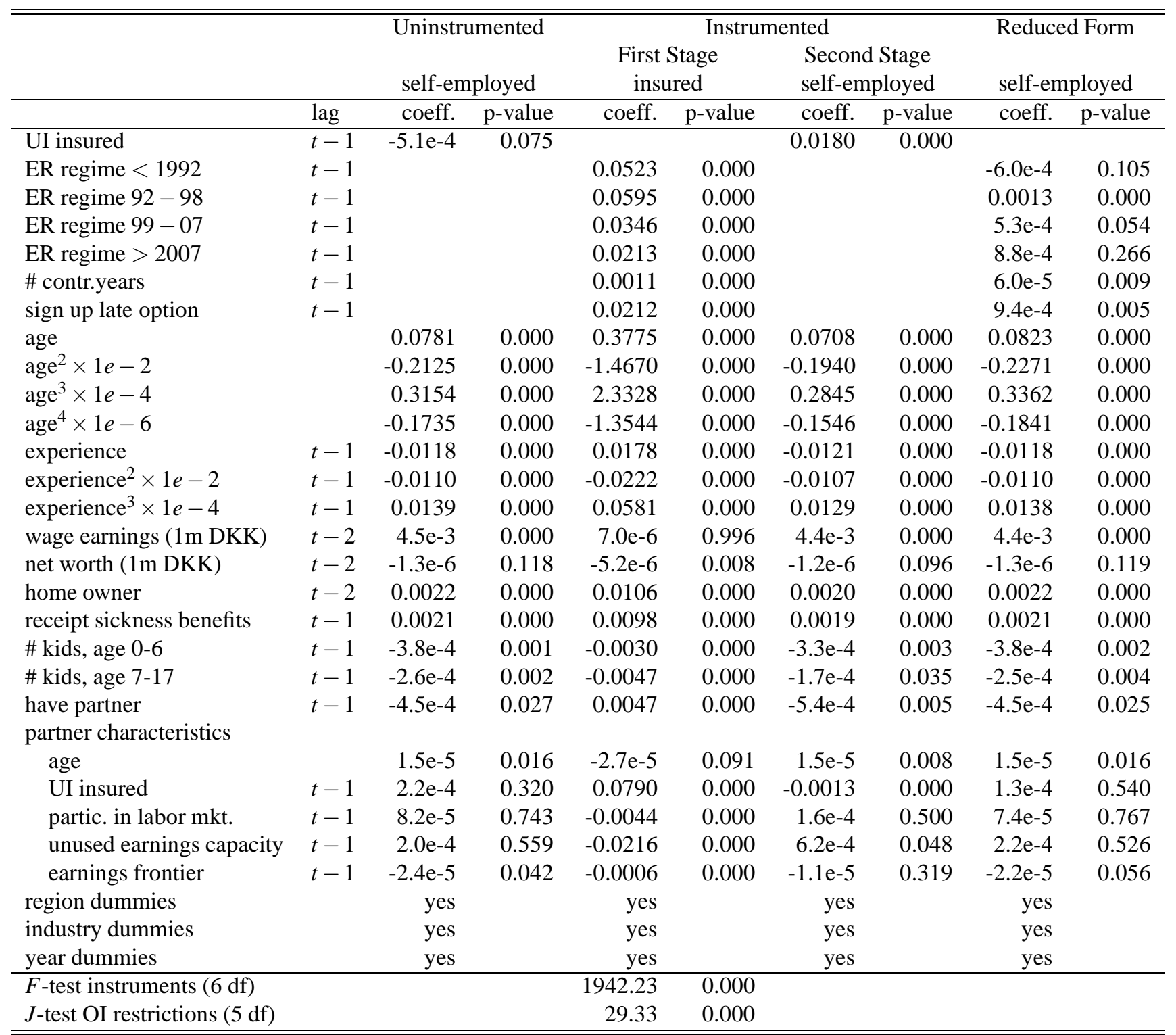

Notes: This Table shows coefficient estimates and associated p-values from three models using the baseline specification. The first set of columns is a linear fixed effects regression (without instrumentation), the second set of columns displays the first stage of a linear fixed effects instrumental variable model, the third set of columns displays the second stage of that model. The fourth set displays a reduced form regression where we use the instruments directly instead of the insurance choice. Based on a $25 \%$ sample, size: 3,372,378 observations from 317,467 individuals. Money amounts deflated to 2005. Statistics and p-values based on heteroskedasticity-corrected robust variance-covariance matrix. 
Table 7: Start-Up: Sensitivity Analyses

\begin{tabular}{|c|c|c|c|c|c|c|c|}
\hline \multirow[t]{3}{*}{ Line } & \multirow[t]{2}{*}{ Model/Variation } & \multicolumn{2}{|c|}{ UI fund member, $t-1$} & \multirow{2}{*}{$\begin{array}{l}F \text {-Test } \\
\text { statistic }\end{array}$} & \multirow{2}{*}{$\begin{array}{l}J \text {-Test } \\
\text { p-value }\end{array}$} & \multirow[b]{2}{*}{$N T$} & \multirow[b]{2}{*}{$N$} \\
\hline & & coeff. & p-value & & & & \\
\hline & baseline (FE-IV model, Table 6) & 0.0180 & 0.0000 & 1942.2 & 0.0000 & $3,372,378$ & 317,467 \\
\hline 1 & random effects (RE) IV model & 0.0170 & 0.0000 & 3549.3 & 0.0000 & $3,403,317$ & 348,406 \\
\hline 2 & RE-IV model, Chamberlain/Mundlak & 0.0119 & 0.0000 & 3584.6 & 0.0000 & $3,403,317$ & 348,406 \\
\hline 3 & $\begin{array}{l}\text { macro variables instead of time dummies } \\
\text { (growth, unemployment and bankruptcies) }\end{array}$ & 0.0066 & 0.0010 & 4550.7 & 0.0000 & $3,372,378$ & 317,467 \\
\hline 4 & 3rd degree age polynomial & 0.0133 & 0.0000 & 1790.9 & 0.0000 & $3,372,378$ & 317,467 \\
\hline 5 & age dummies replace age polynomial & 0.0155 & 0.0000 & 1924.9 & 0.0015 & $3,372,378$ & 317,467 \\
\hline 6 & only age and year dummies as controls & 0.0097 & 0.0013 & 2113.1 & 0.0000 & $4,075,203$ & 357,693 \\
\hline 7 & not controlling for wealth or home ownership & 0.0092 & 0.0028 & 2111.8 & 0.0000 & $3,851,524$ & 342,738 \\
\hline 8 & $\begin{array}{l}\text { dep. var.: dummy for earning } 62.5 \% \text { or more } \\
\text { from self-employment }\end{array}$ & 0.0190 & 0.0000 & 1941.7 & 0.0001 & $3,370,981$ & 317,326 \\
\hline 9 & $\begin{array}{l}\text { sample excluding workers affected by } \\
\text { closures of firms }\end{array}$ & 0.0173 & 0.0000 & 1905.4 & 0.0000 & $3,254,648$ & 313,440 \\
\hline 10 & $\begin{array}{l}\text { sample excluding workers affected by } \\
\text { closure of firms or large layoffs }\end{array}$ & 0.0175 & 0.0000 & 1867.7 & 0.0000 & $3,209,957$ & 312,524 \\
\hline 11 & smaller set of instruments & 0.0156 & 0.0000 & 2808.7 & 0.0001 & $3,372,378$ & 317,467 \\
\hline
\end{tabular}

Notes: This Table reports the estimated coefficient of interest (on the insurance dummy) in the equation of self-employment start-up, when the specification of model assumptions are being changed compared to the main results in Table 6. All estimates are based on a $25 \%$ sample. Full results are available on request. Variation in lines 1 and 2 are based on random effects specifications, including individuals observed just once; line 2 conditions on time-averages of time-varying variables as well; both sets of results control in addition to the baseline for broad cohort effects (dummies) and years of education; column ' $F$-Test statistic' reports $\chi^{2}$ tests for joint significance for RE models. Line 3-11 are FE-IV models as in the baseline. Line 3 uses real GDP growth (per capita), regional unemployment rates, and bankruptcy rates instead of year dummies. Line 4 has the baseline regressors but age dummies instead of a polynomial, line 5 only has a 3rd degree age polynomial. Line 6 only has full sets of age and year dummies (subject to restrictions) as regressors. Line 7 omits wealth and home-ownership from the baseline. Line 8 uses as dependent variable an indicator based on the share of self-employment/business income in total income. Line 9 excludes workers working in firms that are bound to be closed, following Browning and Heinesen (2012). Line 10 in addition excludes workers from firms where large layoffs were observed. Line 11 omits the last 2 instruments from the baseline. 
Table 8: Start-Up: Heterogeneous Effects

\begin{tabular}{|c|c|c|c|c|c|c|c|}
\hline \multirow[t]{3}{*}{ Line } & \multirow[t]{2}{*}{ Model/Variation } & \multicolumn{2}{|c|}{ UI fund member, $t-1$} & \multirow{2}{*}{$\begin{array}{r}F \text {-Test } \\
\text { statistic }\end{array}$} & \multirow{2}{*}{$\begin{array}{r}J \text {-Test } \\
\text { p-value }\end{array}$} & \multirow[b]{2}{*}{$N T$} & \multirow[b]{2}{*}{$N$} \\
\hline & & coeff. & p-value & & & & \\
\hline & baseline (FE-IV model, Table 6) & 0.0180 & 0.0000 & 1942.2 & 0.0000 & $3,372,378$ & 317,467 \\
\hline 1 & sample split by time & & & & & & \\
\hline a & $-1980-1998$ & -0.0048 & 0.3673 & 1870.8 & 0.0065 & $1,748,187$ & 217,407 \\
\hline $\mathrm{b}$ & - 1993-2009 & 0.0495 & 0.0000 & 203.6 & 0.9445 & $2,442,435$ & 263,565 \\
\hline 2 & sample split by education & & & & & & \\
\hline a & - low & 0.0042 & 0.5952 & 269.4 & 0.0000 & 806,611 & 87,360 \\
\hline $\mathrm{b}$ & — intermediate & 0.0279 & 0.0000 & 804.6 & 0.0003 & $1,709,774$ & 163,445 \\
\hline C & — high & 0.0047 & 0.2831 & 913.6 & 0.2097 & 734,585 & 67,385 \\
\hline 3 & sample split by marital status & & & & & & \\
\hline a & — not partnered & 0.0364 & 0.0000 & 340.1 & 0.0209 & $1,142,460$ & 161,320 \\
\hline $\mathrm{b}$ & — partnered & 0.0133 & 0.0006 & 1323.2 & 0.0236 & $2,209,249$ & 218,429 \\
\hline 4 & sample split by home ownership & & & & & & \\
\hline a & — home owner & 0.0263 & 0.0000 & 1623.0 & 0.0000 & $2,523,280$ & 246,780 \\
\hline $\mathrm{b}$ & — no home owner & 0.0265 & 0.0132 & 120.3 & 0.5010 & 809,300 & 142,402 \\
\hline 5 & sample split by innovative industry & & & & & & \\
\hline a & — non-innovative & 0.0182 & 0.0000 & 1702.2 & 0.0000 & $2,905,441$ & 288,691 \\
\hline $\mathrm{b}$ & — innovative & 0.0136 & 0.0029 & 386.9 & 0.6472 & 439,187 & 48,136 \\
\hline
\end{tabular}

Notes: This Table reports the estimated coefficient of interest (on the insurance dummy) in the equation of self-employment start-up, when the specification of model assumptions are being changed compared to the main results in Table 6 , and the sample is conditioned on particular strata. All estimates are based on a $25 \%$ sample and are obtained from FE-IV models. Full results are available on request. Variations in lines 1-5 split by year of observation, education level, marital status, home ownership, and the OECD (2011) classification of innovativeness of industry. 
Table 9: Firm Performance Measures for Firms Starting Up in Year $t$, by Insurance Status in $t-1$

\begin{tabular}{lrrrr}
\hline \hline & Insured & Uninsured & Difference & $N$ \\
\hline Survival until $t+3(\%)$ & 44.81 & 37.54 & $7.27^{* * *}$ & 179,581 \\
Conditional on survival until $t+3:$ & & & & \\
(all measurements at $t+3)$ & & & & \\
$\quad$ Mean profit & 376 & 409 & $-33^{* * *}$ & 67,742 \\
Median profit & 313 & 288 & $25^{* * * *}$ & 67,742 \\
Fraction with profit $\leq 0(\%)$ & 8.18 & 13.07 & $-4.89^{* * *}$ & 67,742 \\
Sales Revenues & 3349 & 5652 & $-2303^{* * *}$ & 42,447 \\
Value added & 1520 & 3033 & $-1513^{* * * *}$ & 42,447 \\
Exports & 149 & 289 & $-140^{* * *}$ & 42,447 \\
Fraction with employees $(\%)$ & 37.80 & 31.47 & $6.33^{* * *}$ & 76,216 \\
\hline \hline
\end{tabular}

Note: Survival until $t+3$ means: being self-employed in $t+s, s=1,2$.3. Profit measured at $t+3 \in[1987-$ 2009]. Value added (sales minus expenses, not wages) and exports are measured at $t+3 \in[1990-2007]$. All financial variables are measures in constant $2005 \mathrm{k}$ DKK. Having employees is measured at $t+3 \in[1990-$ 2009]. Asterisks indicate significance levels: $* * *=1 \%$ or lower. 
Table 10: Firm Performance Measures: IV Regression Analysis

\begin{tabular}{|c|c|c|c|c|c|c|c|}
\hline & & \multicolumn{2}{|c|}{ Survival until $t+3$} & \multicolumn{2}{|c|}{ Profits $t+3$} & \multicolumn{2}{|c|}{ Employer $t+3$} \\
\hline & lag & coeff. & p-value & coeff. & $\mathrm{p}$-value & coeff. & p-value \\
\hline UI insured & $t-1$ & -0.0270 & 0.898 & 32.721 & 0.824 & -0.0271 & 0.864 \\
\hline age & & 0.0699 & 0.788 & -63.050 & 0.650 & 0.5299 & 0.005 \\
\hline $\operatorname{age}^{2} \times 1 e-2$ & & 0.2946 & 0.753 & 169.043 & 0.749 & -1.7674 & 0.006 \\
\hline $\operatorname{age}^{3} \times 1 e-4$ & & -0.4806 & 0.754 & -232.657 & 0.789 & 2.9619 & 0.005 \\
\hline $\operatorname{age}^{4} \times 1 e-6$ & & 0.2921 & 0.754 & 110.753 & 0.834 & -1.8140 & 0.004 \\
\hline experience & $t-1$ & 0.0112 & 0.070 & -5.165 & 0.356 & 0.0169 & 0.000 \\
\hline experience $^{2} \times 1 e-2$ & $t-1$ & -0.0346 & 0.297 & 22.306 & 0.428 & -0.0583 & 0.020 \\
\hline experience $^{3} \times 1 e-4$ & $t-1$ & 0.0531 & 0.400 & -55.955 & 0.279 & 0.0615 & 0.185 \\
\hline wage earnings ( $1 \mathrm{~m}$ DKK) & $t-2$ & -0.1071 & 0.040 & 419.361 & 0.000 & 0.1956 & 0.000 \\
\hline net worth (1m DKK) & $t-2$ & $-4.0 \mathrm{e}-5$ & 0.000 & -0.055 & 0.174 & $4.0 \mathrm{e}-5$ & 0.254 \\
\hline home owner & $t-2$ & 0.0651 & 0.000 & 36.546 & 0.000 & 0.0452 & 0.000 \\
\hline receipt sickness benefits & $t-1$ & -0.0018 & 0.927 & -59.291 & 0.000 & -0.0452 & 0.000 \\
\hline \# kids $0-6$ & $t-1$ & 0.0012 & 0.850 & 17.772 & 0.000 & 0.0077 & 0.095 \\
\hline \# kids 7-17 & $t-1$ & -0.0117 & 0.024 & 15.724 & 0.000 & 0.0222 & 0.000 \\
\hline have partner & $t-1$ & -0.0058 & 0.498 & 17.583 & 0.002 & 0.0115 & 0.065 \\
\hline partner characteristics & & & & & & & \\
\hline age & & $8.6 e-4$ & 0.004 & 0.960 & 0.000 & $3.8 \mathrm{e}-4$ & 0.057 \\
\hline UI insured & $t-1$ & 0.0336 & 0.525 & -14.244 & 0.685 & 0.0117 & 0.759 \\
\hline partic. in labor mkt. & $t-1$ & 0.0211 & 0.073 & -11.431 & 0.180 & 0.0273 & 0.001 \\
\hline unused earnings capacity & $t-1$ & $4.7 e-4$ & 0.976 & -8.065 & 0.459 & $3.5 \mathrm{e}-4$ & 0.973 \\
\hline earnings frontier & $t-1$ & $-8.8 \mathrm{e}-4$ & 0.172 & 0.828 & 0.041 & $-3.4 \mathrm{e}-4$ & 0.405 \\
\hline years of education & & 0.0055 & 0.000 & 14.641 & 0.000 & 0.0098 & 0.000 \\
\hline year of birth dummies & & yes & & yes & & yes & \\
\hline region dummies & & yes & & yes & & yes & \\
\hline industry dummies & & yes & & yes & & yes & \\
\hline year dummies & & yes & & yes & & yes & \\
\hline Sample & & $25 \%$ & & $100 \%$ & & $100 \%$ & \\
\hline$N$ & & 28,131 & & 59,142 & & 55,730 & \\
\hline$F$ test (statistic, p-value) & & 7.80 & 0.000 & 16.84 & 0.000 & 13.59 & 0.000 \\
\hline$J$ test (statistic, p-value) & & 2.88 & 0.4109 & 0.35 & 0.9500 & 2.19 & 0.5349 \\
\hline
\end{tabular}

Notes: This Table shows IV (2SLS) estimates of firm performance (outcomes) after start-up, where insurance is allowed to be endogenous, and instrumented with the ER policy reforms. First stage results are available on request. Money amounts deflated to 2005. The estimates for survival are conditional on entering self-employment from wage employment between periods $t-1$ and $t$. The estimates for profits and being an employer are conditional on entering self-employment from wage employment between periods $t-1$ and $t$ and on surviving in self-employment every year until year $t+3$. Standard errors underlying the $\mathrm{p}$-values have been clustered at the individual level. 
Table 11: Firm Performance (Survival and Employees): Sensitivity Analyses

\begin{tabular}{|c|c|c|c|c|c|c|c|c|c|}
\hline \multirow{2}{*}{\multicolumn{2}{|c|}{ Variation }} & \multirow[b]{2}{*}{ IV? } & \multicolumn{2}{|c|}{$\overline{\mathrm{UI}}$ fund member, $t-1$} & \multirow{2}{*}{$\begin{array}{r}F \text { test } \\
\text { statistic }\end{array}$} & \multirow{2}{*}{$\begin{array}{r}J \text { test } \\
\text { p-value }\end{array}$} & \multirow[b]{2}{*}{$N T$} & \multirow[b]{2}{*}{$N$} & \multirow[b]{2}{*}{ Sample } \\
\hline & & & coeff. & p-value & & & & & \\
\hline & Survival & & & & & & & & \\
\hline SO & baseline (survival until $t+3$, Table 10) & yes & -0.0270 & 0.8975 & 7.80 & 0.4109 & 28,131 & & $25 \%$ \\
\hline S1 & survival until $t+5$ & yes & 0.2358 & 0.2440 & 8.43 & 0.8981 & 24,004 & & $25 \%$ \\
\hline S2 & survival until $t+3$ & no & 0.0985 & 0.0000 & - & - & 28,131 & & $25 \%$ \\
\hline S3 & survival until $t+5$ & no & 0.0929 & 0.0000 & - & - & 24,004 & & $25 \%$ \\
\hline S 4 & survival until $t+3$, full-time & yes & 0.0822 & 0.6866 & 7.80 & 0.1705 & 28,131 & & $25 \%$ \\
\hline S5 & joint probability of entry and survival until $t+3$ & yes & 0.0183 & 0.0000 & 2691.85 & 0.4094 & $3,033,048$ & 288,059 & $25 \%$ \\
\hline \multirow[t]{2}{*}{ S6 } & joint probability of entry and survival until $t+5$ & yes & 0.0223 & 0.0000 & 2337.23 & 0.0000 & $2,544,588$ & 283,124 & $25 \%$ \\
\hline & Employees & & & & & & & & \\
\hline E0 & baseline (have employees $t+3$, Table 10) & yes & -0.0271 & 0.8641 & 13.59 & 0.5349 & 55,730 & & $100 \%$ \\
\hline E1 & have employees $t+5$ & yes & -0.1401 & 0.3712 & 14.49 & 0.0934 & 39,541 & & $100 \%$ \\
\hline E2 & have employees $t+3$ & no & 0.0066 & 0.1744 & - & - & 55,730 & & $100 \%$ \\
\hline E3 & have employees $t+3$ and full-time & yes & -0.0551 & 0.7613 & 10.87 & 0.4469 & 44,781 & & $100 \%$ \\
\hline E4 & have employees $t+3$ (alternative measure) & yes & -0.1747 & 0.2763 & 13.59 & 0.3247 & 55,730 & & $100 \%$ \\
\hline E5 & have employees $t+3$ (alternative measure, $\geq 1986$ ) & yes & -0.3750 & 0.0100 & 16.84 & 0.2386 & 59,142 & & $100 \%$ \\
\hline E6 & number of employees $t+3$ & yes & 112.9364 & 0.0818 & 13.59 & 0.6655 & 55,730 & & $100 \%$ \\
\hline
\end{tabular}

Notes: This Table reports the estimated coefficient of interest (on the insurance dummy) in various equations of firm performance measures, when the specification of model assumptions are being changed compared to the main results in Table 10. Full results are available on request. Line S1 measures survival until $t+5$. Lines S2 and S3 deviate from S0 and S1 by not instrumenting the UI choice. Line S4 considers survival of those that do not earn wage income at the same time. Lines S5 and S6 are similar to S0 and S1 but do not condition on start-up, but instead consider the joint probability of starting up and surviving; both estimates are based on panel data models similar to those in Table 6. Lines E1, E2 and E3 present variations for having employees, likened to those in lines S1, S2, and S4, respectively. Lines E4 and E5 are based on headcounts of employees at an establishment ID at the record date of the matched employer/employee data; this measure can be constructed until the beginning of our data in 1980, the estimation sample starts in 1986 due to the restriction on wealth that we use as regressor; line E4 uses the same time window as the baseline E0, line E5 extends the sample back in time. Line 6 returns to the baseline data but uses the continuous measure of employees rather than the binary employment indicator. 
Table 12: Firm Performance (Financial Outcomes): Sensitivity Analyses

\begin{tabular}{rlrrrrrr}
\hline \hline \multirow{2}{*}{ Variation } & \multicolumn{5}{c}{ UI fund member, $t-1$} & $F$ test & $J$ test \\
F1 & profits $t+3$ (baseline, Table 10) & yes & 32.721 & 0.8245 & 16.84 & 0.9500 & 59,142 \\
F1 & value added $t+3$ & yes & $1.4 \mathrm{e}+4$ & 0.1430 & 10.65 & 0.7470 & 40,776 \\
F2 & sales $t+3$ & yes & $1.2 \mathrm{e}+4$ & 0.3124 & 10.65 & 0.9947 & 40,776 \\
F3 & exports $t+3$ & yes & $9.9 \mathrm{e}+2$ & 0.3131 & 10.65 & 0.8434 & 40,776 \\
F4 & business income $t+3$ & yes & 31.914 & 0.8235 & 16.84 & 0.9223 & 59,142 \\
F5 & average profits $t+3$ through $t+5$ & yes & $-1.9 \mathrm{e}+2$ & 0.2006 & 14.49 & 0.6519 & 39,541 \\
F6 & total income $t+3$ & yes & -49.196 & 0.5895 & 36.13 & 0.4662 & 113,497 \\
F7 & net worth $t+3$ & yes & $2.2 \mathrm{e}+3$ & 0.6560 & 38.39 & 0.6457 & 103,391 \\
F8 & change in net worth $t-1 \rightarrow t+3$ & yes & $2.4 \mathrm{e}+3$ & 0.6198 & 38.39 & 0.6475 & 103,391 \\
F10 & profits $t+3$ & no & -14.123 & 0.0078 & - & - & 59,142 \\
F11 & value added $t+3$ & no & $-1.1 \mathrm{e}+3$ & 0.0003 & - & - & 40,776 \\
F12 & sales $t+3$ & no & $-1.7 \mathrm{e}+3$ & 0.0000 & - & - & 40,776 \\
F13 & exports $t+3$ & no & -75.402 & 0.0125 & - & - & 40,776 \\
F14 & business income $t+3$ & no & -13.239 & 0.0094 & - & - & 59,142 \\
F15 & average profits $t+3$ through $t+5$ & no & -37.185 & 0.0000 & - & - & 39,541 \\
F16 & total income $t+3$ & no & -36.556 & 0.0000 & - & - & 113,497 \\
F17 & net worth $t+3$ & no & $-4.8 \mathrm{e}+2$ & 0.0370 & - & - & 103,391 \\
F18 & change in net worth $t-1 \rightarrow t+3$ & no & $-4.8 \mathrm{e}+2$ & 0.0375 & - & - & 103,391 \\
\hline \hline
\end{tabular}

Notes: This Table reports the estimated coefficient of interest (on the insurance dummy) in various equations of firm performance measures, when the specification of model assumptions are being changed compared to the main results in Table 10 . Profits, value added, sales and exports are in 1000 DKK. Wealth and total income measures in 10k DKK. Full results are available on request. The data is the full population (100\%). Lines F0-F8 display results using different outcome measures when instrumenting the UI choice, Lines F10-F18 show the corresponding coefficient estimates for uninstrumented regressions. Profits (lines F0/F10) include, business income (lines F4/F14) excludes retained earnings. Total income, net worth and its change (lines F6-F8/F16-F18) refer to the personal income and wealth variables of the owner-entrepreneur, and the sample does not condition on survival as self-employed until $t+3$. 


\section{Appendix B Proofs}

\section{Appendix B.1 Investment}

The optimal investment of an entrepreneur is determined from the first order condition applied to (1) with respect to $k$ when $d=1$ :

$$
F(k) \equiv-\pi^{1} u^{\prime}\left(A+Y_{0}^{1 s}\right)+\left(1-\pi^{1}\right)\left(\gamma \alpha k^{\alpha-1}-1\right) u^{\prime}\left(A+Y_{1}^{1 s}\right)=0 .
$$

Income per state of the world is

$$
\begin{aligned}
& Y_{0}^{1 s}=s(B-P)+(1-s) H-k \\
& Y_{1}^{1 s}=\gamma k^{\alpha}-k-s \cdot P .
\end{aligned}
$$

Where $\gamma k^{\alpha}-k$ are profits. Owing to concavity of $u, F$ decreases monotonically with $k$

$$
F_{k}=\underbrace{\pi^{1} u^{\prime \prime}\left(A+Y_{0}^{1 s}\right)}_{\leq 0}+\underbrace{\left(1-\pi^{1}\right)}_{\geq 0}[\underbrace{(\alpha-1)}_{<0} \underbrace{\gamma \alpha k^{\alpha-2} u^{\prime}\left(A+Y_{1}^{1 s}\right)}_{>0}+\underbrace{\left(\gamma \alpha k^{\alpha-1}-1\right)^{2}}_{\geq 0} \underbrace{u^{\prime \prime}\left(A+Y_{1}^{1 s}\right)}_{<0}] \leq 0 .
$$

Consider now the profit-maximizing value $\bar{k} \equiv(\gamma \alpha)^{1 /(1-\alpha)}$. We can bracket the optimal $k^{*}$ to lie in the interval $[0 ; \bar{k}]$ : for $\pi^{1}=0$ obviously $k^{*}=\bar{k}$ since then $F(\bar{k})=0$; for $\pi^{1}>0$ obtains $F(\bar{k})<0$, implying $k^{*}<\bar{k}$ because of monotonicity of $F$ with a lower bound of 0 .

To establish how $k^{*}$ varies with a model parameter $\theta \in\left\{\pi^{1}, s, B, P, H, A, \gamma, \alpha\right\}$, we differentiate implicitly, $\frac{\mathrm{d} k}{\mathrm{~d} \theta}=-\frac{F_{\theta}}{F_{k}}$. The sign of $\mathrm{d} k / \mathrm{d} \theta$ is equal to the sign of $F_{\theta}$, since $F_{k} \leq 0 . \quad F_{\theta}$ can easily be determined when $k^{*} \leq \bar{k}$ except for $\theta \in\{\gamma, \alpha\}$. Given $k^{*}$, envelope conditions apply.

With $s$ binary we write $k^{s *}$ to distinguish between the non-insured $s=0$ and insured $s=1$. The signs of the derivatives can then be succinctly summarized as follows when $k^{*} \leq \bar{k}$

$$
\begin{aligned}
& k^{0 *}=k\left(\pi_{-}^{1}, \underset{+}{H}, \underset{+}{A}, \underset{?}{\gamma}, \underset{?}{\alpha}\right) \\
& k^{1 *}=k\left(\pi_{-}^{1}, \underset{+}{B, P}, \underset{+}{A}, \underset{?}{\gamma}, \underset{?}{\alpha}\right) .
\end{aligned}
$$

For given values of $A, \gamma, \alpha$ and $\pi^{1}, k^{1 *}-k^{0 *} \geq 0$ : the insured invest at least as much as the uninsured. 


\section{Appendix B.2 Insurance Choice}

Evaluating expected utility for an entrepreneur for the two cases of being and not being insured at the optimal investment level shows that the expected utility difference between insured and uninsured depends on $\pi^{1}, B, P, H, A, \gamma$ and $\alpha$ :

$$
\begin{aligned}
E U^{11}-E U^{10} & =\pi^{1} \cdot\left[u\left(A-k^{1 *}+B-P\right)-u\left(A-k^{0 *}+H\right)\right] \\
& +\left(1-\pi^{1}\right) \cdot\left[u\left(A-k^{1 *}+\gamma\left(k^{1 *}\right)^{\alpha}-P\right)-u\left(A-k^{0 *}+\gamma\left(k^{0 *}\right)^{\alpha}\right)\right] .
\end{aligned}
$$

The optimal insurance choice conditional on occupation $d$ can be written as $s^{d *}=\mathbf{1}\left[E U^{d 1}-E U^{d 0}>\right.$

$0]$ where $\mathbf{1}[\cdot]$ is an indicator function taking value 1 if the argument is true, and 0 otherwise. For entrepreneurs, $s^{1 *}$ reacts to changes in various model parameters as follows:

$$
s^{1 *}=s\left(\underset{?}{\left.\pi^{1}, B, P,+\underset{+}{\operatorname{H}}, \underset{?}{A}, \underset{?}{\gamma}, \underset{?}{\alpha}\right)}\right.
$$

Similarly, from the expected utility difference for an insured and uninsured wage earner,

$$
E U^{01}-E U^{00}=\pi^{0} \cdot[u(A+B-P)-u(A+H)]+\left(1-\pi^{0}\right) \cdot\left[u\left(A+Y^{W}-P\right)-u\left(A+Y^{W}\right)\right]
$$

we determine that the insurance choice depends on parameters as follows

$$
s^{0 *}=s\left(\underset{+}{\pi_{+}^{0}, B, P,{ }_{-}^{H}, \underset{?}{A}, Y_{+}^{W}}\right) .
$$

\section{Appendix B.3 Occupational choice}

The agent will choose to become an entrepreneur rather than being a wage earner if, conditional on optimal investment and on insurance status, $d^{s *}=\mathbf{1}\left[E U^{1 s}-E U^{0 s}>0\right]=1$. For the uninsured, $s=0$,

$E U^{10}-E U^{00}=\pi^{1} u\left(A-k^{0 *}+H\right)+\left(1-\pi^{1}\right) u\left(A+\gamma\left(k^{0 *}\right)^{\alpha}-k^{0 *}\right)-\pi^{0} u(A+H)-\left(1-\pi^{0}\right) u\left(A+Y^{W}\right)$. 
Taking partial derivatives implies

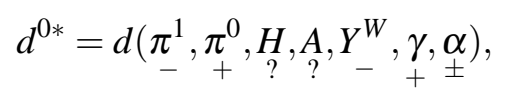

where we have assumed that firm profits or wage earnings exceed $H$ in order to determine the sign for $\pi^{d}$. The sign for $\alpha$ is negative if $k<1$ and positive for $k>1$.

Similarly, for the insured, $s=1$,

$E U^{11}-E U^{01}=\pi^{1} u\left(A-k^{0 *}+B-P\right)+\left(1-\pi^{1}\right) u\left(A-P+\gamma\left(k^{0 *}\right)^{\alpha}-k^{0 *}\right)-\pi^{0} u(A+B-P)-\left(1-\pi^{0}\right) u\left(A+Y^{W}-P\right)$,

and thus,

$$
d^{1 *}=d\left(\pi_{-}^{1}, \pi_{+}^{0}, \underset{?}{B, P}, \underset{?}{A}, Y_{-}^{W}, \underset{+}{\gamma}, \underset{ \pm}{\alpha}\right)
$$

where we have assumed that firm profits or wage earnings exceed $B$ in order to determine the sign for $\pi^{d}$. A sufficient condition for the sign for $B$ to be positive is $\pi^{1}>\pi^{0}$. The sign for $\alpha$ is negative if $k<1$ and positive for $k>1$. 